\title{
Triterpene sapogenins with oleanene skeleton: chemotypes and biological activities
}

\author{
Kamil Jatczak and Grzegorz Grynkiewicz \\ Pharmaceutical Research Institute, Warsaw, Poland
}

\begin{abstract}
Critical survey of a selected class of pentacyclic triterpenes - the oleanane family, is presented based on current literature in order to underline their value for medicinal chemistry and drug development potential. Oleanenes may be considered as a renewable resource of valuable research materials which are structurally diverse, inherently biocompatible and have built-in affinity for many categories of functional proteins. Although availability of particular compounds from natural sources may be very low, synthetic methods elaborated by generations of chemists, secure a way to obtaining desirable structures from commercial starting materials.
\end{abstract}

Key words: pentacyclic triterpenes, oleanane derivatives, oleanolic acid exploratory chemistry and experimental pharmacology

Received: 18 February, 2014; revised: 16 April, 2014; accepted: 29 April, 2014; available on-line: 11 June, 2014

\section{INTRODUCTION}

Pentacyclic triterpenes (PT'T) constitute a large class of natural products widespread in the Plant Kingdom (Azimova, 2013; Dinda et al., 2010). Extraordinary structural diversity in this category of secondary metabolites has fascinated chemists and biologists alike for well over half a century. Chemical concept of the biogenetic "isoprene rule" as a basis of terpenoid assembly in plants, advanced in a seminal paper by Swiss chemists (Eschenmoser et al., 1955) has been recapitulated upon the publication 50-thieth anniversary, with appropriate commentaries, outlining the substantial field of natural product research related to biomimetic carbocyclization which leads to triterpenoids and steroids (Eshenmoser \& Arigoni, 2005). Parallel effort of biosynthetic studies afforded definite conclusion, that despite many possible pathways executed by highly specific squalene cyclases (OSC), a given PTT comprising five carbocycles and eight centers of chirality is assembled in a single enzymatic step from common linear precursor (Lodeiro et al., 2007; Pollier et al., 2013). Although knowledge of biosynthesis, including active sites topology of specific squalene cyclases, and structures of terpenoids in plants is presently well established, their biological functions are not entirely understood. Nevertheless, it is generally recognized that biogenesis of terpenes as such and also in their glycosylated forms (e.g. as saponins) must offer some advantage of environmental nature to the plant host, which tends to be evolutionary favored and genetically preserved. The present view of triterpene biosynthesis constitute of three distinct groups of enzymat- ic transformations: 2,3-oxidosqualene cyclization, which results in formation of such triterpene skeletons as oleanane, ursane, hopane, etc. (Pollier et al., 2013); action of cytochrome type multifunctional oxidases, which are responsible for introduction of hydroxyl groups and also their subsequent oxidations (Fukushima et al., 2011); action of acylases and glycosyltransferases, which complete the chain of events leading to saponins which are the end products of chemical defence and allelopathic chemicals mediating interspecies interactions (Geisler et al., 2013). Historically, biological activity of saponins attracted more attention than their respective triterpene aglycons (genins) (Hostettmann \& Marston, 2005; Negi et al., 2013). More recently, it has been realized that various natural triterpenes exhibit pleiotropic activity towards plethora of molecular targets, generating much interest of researchers and considerable potential for pharmacological studies (Sun et al., 2006; Zwenger \& Basu, 2008; Sheng \& Sun, 2011). Yet, in general perception significance of triterpenes as prospective new drug leads is rather underscored. In order to explore and discuss their potential in some methodical way, we decided to present some structural, chemical and biological activity research data, for a restricted group of compounds, representing various chemotypes placed within strictly defined molecular framework of a particular type of triterpene skeleton originating from typical biogenetic pathway. Our choice of $\beta$-amyrin (BAR, 3) sub-class of pentacyclic triterpenes stems from their considerable widespread occurrence and relatively good availability of pure chemical entities, which were studied as biologically active plant constituents but also gave rise to several generations of semisynthetic derivatives bearing functionalities not found in Nature. Obviously, such choice is artificial in view of well known diversity of the squalene cyclization processes, which involves variety of OSC enzymes of different selectivity (Augustin et al., 2011). Although many plants contain terpenoid secondary metabolites which result from various parallel biogenetic pathways, this review purposely focuses on only one selected type of terpenoid framework (scaffold), in order to seek and discuss pos-

e-mail: g.grynkiewicz@ifarm.eu

Abbreviations: API, active pharmaceutical ingredient; BAR, $\beta$-amyrin; BAC, $\beta$-amyrin cyclase; BAS, $\beta$-amyrin synthase; CYP, cytochrome $\mathrm{P} 450$, heme-related monooxidase; COX-2, cyclooxygenase type 2; CDDO, 2-cyano-3,12-dioxooleana-1,9(11)-dien-28-oic acid; CDDOMe, bardoxolone, 2-cyano-3,12-dioxooleana-1,9(11)-dien-28-oic acid methyl ester; DMAP, 4-dimethylaminopyridine; EDCl, 1-(3-dimethylaminopropyl)-3-ethylcarbodiimide hydrochloride; GTS, glycosyltransferase; HCSE, horse chestnut seed extract; HCV, hepatitis $C$ virus; IKK $\beta$, subunit of IkappaB kinase complex; iNOS, inducible nitrogen oxide synthase; NFKB, nuclear factor kappa $B$ Nrf2, nuclear protein activating Antioxidant Response Element; OSC, oxidosqualene cyclase; PTT, pentacyclic triterpenes; SAR, structure-activity relationship 
sible differences in biological activities between various products of enzymatic oxidations and secondary derivatizations. Triterpenes are abundant in many dicotyledonous plants (over 80 families are involved; there are over 20000 of individual triterpenoid natural products), mainly in glycosylated form, as mono- and bis-desmosidic saponins (Azimova 2013; Dinda et al., 2010) and $\beta$-amyrin can be considered the simplest, most popular aglycone of the class and a model scaffold structure for triterpene based natural and semisynthetic pharmacophores. Since 1985, newly isolated triterpenes are regularly covered in annual review initiated by the Royal Chemical Society (Hill \& Connolly, 2013 and earlier annual reports).

\section{HYDROXYLATED PENTACYCLIC TRITERPENES (PTT) DERIVED FROM OLEANYL CATION}

(S)-2,3-Epoxysqualene, which results from biogenetic condensation of isoprenoid phosphates, undergoes in Nature a sequence of enzymatic transformations, producing carbocationic PTT intermediates (Xue et al., 2012), which can undergo Wagner-Merwein type rearrangements but are also susceptible to a spontaneous stabilization with concomitant formation of an olefinic bond as illustrated on the Scheme 1. Condensed pentacyclic framework formed, features characteristic pattern of substitution with residual 3- $\beta$ hydroxyl group, double bond $\Delta-12,13$; eight methyl groups forming two geminal arrangements (at C-4 and C-20), trans- junction of the cyclohexane $\mathrm{ABCD}$ rings and cis-fused rings DE. The corresponding hydrocarbon is known as olean-12-ene, which is a convenient entry for semi-systematic nomenclature for natural and synthetic derivatives. This molecular arrangement, presented on Fig. 1 with some stereochemical details elucidated from X-ray structure determination (Maartmann-Moe et al., 1987; Froelich \& Gzella, 2010) and key carbon atom numbering, is characterized by relatively high thermodynamic stability as evidenced by conformational energetics study conducted by EJ Corey (Surendra \& Corey, 2009). Great many derivatives of $\beta$-amyrin (3) found in plants differ from the prototypic structure mainly by hydroxylation patterns, double bond position and oxidation level (Azimova 2013). Triterpene hydroxyl groups derivatizations found in nature are of two different kinds, stemming from acylation and/or glycosylation and their nearly combinatorial application applied by evolutionary biogenesis in plants generated many collections which can serve as individual chemotaxonomic hallmark of species. It is well established customary idea in phytochemistry, pharmacognosy and related disciplines that saponins, which are natural glycosides featuring various kinds of lipophilic steroidal or terpenoid aglycones constitute a primary subject of their study. Indeed, many triterpenes do not occur in nature in their free state, but only in form of acylated conjugates with mono or oligosaccharides. Saponins are distinct and important category of natural products, which have found their applications early in development of life sciences and their study are amply covered in the literature, from traditional to modern, which leaves them outside the scope of this review.

Our attempt to collect BAR analogs, which are scattered all over the Plant Kingdom, and present them as one structurally related chemical family, comprises compounds of natural origin sharing characteristic $\mathrm{C}_{30}$ oleanane pentacyclic pattern: from primary products of OSC action, through polyhydroxylated neutral genins, to mono- and di- basic carboxylic acids. Their conven-

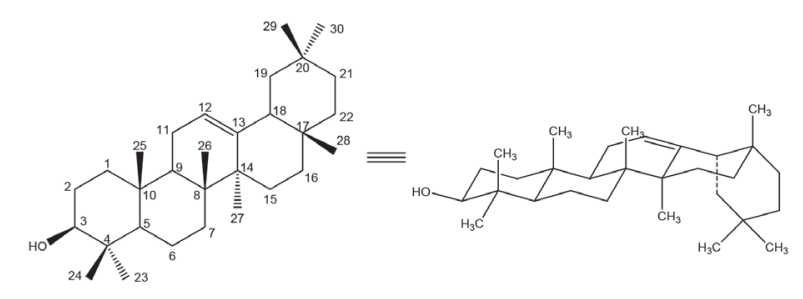

Figure 1. Conventional representations of $\beta$-amyrin structure (equivalent).

tional names usually do not reveal essential structural features; quite frequently a single PTT has several synonymic names, which can be misleading. Neutral BAR derivatives usually feature a double bond (relatively unreactive; typical olean-12-enes are reported to resist catalytic hydrogenation and exhibit atypical reactivity towards oxidative reagents), hydroxyl groups, primary and secondary, of different reactivity. Stereochemistry of secondary hydroxyl groups reflects specificity of particular hydroxylases, which are P450 cytochrome type enzymes (Geisler et al., 2013) characteristic for a given plant species. Typically hydroxylated positions of oleanene skeleton, such as: $2,3,6,11,15,16,21$ and 22 can carry hydroxyl groups of either $\alpha$ - or $\beta$-configuration. Oxo functions are occasionally encountered within BAR analogues, both as aldehyde or keto group. It has to be mentioned that "epoxy" prefix is applied in conventional nomenclature of P'T' in two different meanings: as vicinal and non-vicinal anhydro-diol arrangement, which can be misleading. Acidic function is usually (but not always) revealed in the trivial name of a natural triterpene. Frequently encountered ending: "genin" testifies to origin of newly identified specimen at the time of its discovery as an aglycone of saponins. Apart from venerable attempts at total synthesis, chemistry of simpler PT'T have not been particularly developed, thus relatively succinct descriptions of some hydroxylated oleanenes selected from collection of compounds $1-64$, presented in Table 1. This changes considerably as we enter hydroxylated acid category (Table 2), which can be explained by greater availability of substrates and wider scope of conceivable chemical transformations. Two collections of naturally occurring triterpenes are presented, to illustrate variety of chemotypes encountered within oleanene PT'T family. The choice of molecular objects has been arbitrary, but according to authors intention, it reflects a level of interest measured as a number of available literature references.

\section{$\beta$-AMYRIN AND ISOMERIC OLEANENE MONOOLS}

(3S)-2,3-Epoxysqualene, the key intermediate in biosynthesis of higher isoprenoids, can be cyclized in several manners by plethora of specific enzymes - oxidosqualene cyclases (OSC), and among them $\beta$-amyrin synthases (BAS) are relatively numerous (Xue et al., 2012). $\beta$-Amyrin (3, BAR, also known as $\beta$-amyrenol), occurs in free form and also as fatty acid esters in many plant resins, latexes and waxes (together with $\alpha$-amyrin, which belongs to ursane class of PTT). It has been isolated, among others, from mistletoe, clove, sugar beet, and olive leaves. Following a wave of TPP total syntheses (in racemic form) started around 1970, enantioselective methods have been developed, culminating in synthesis of $\mathbf{3}$ and some analogs by EJ Corey (Surendra \& Corey, 2009). The syntheses are listed among highest 


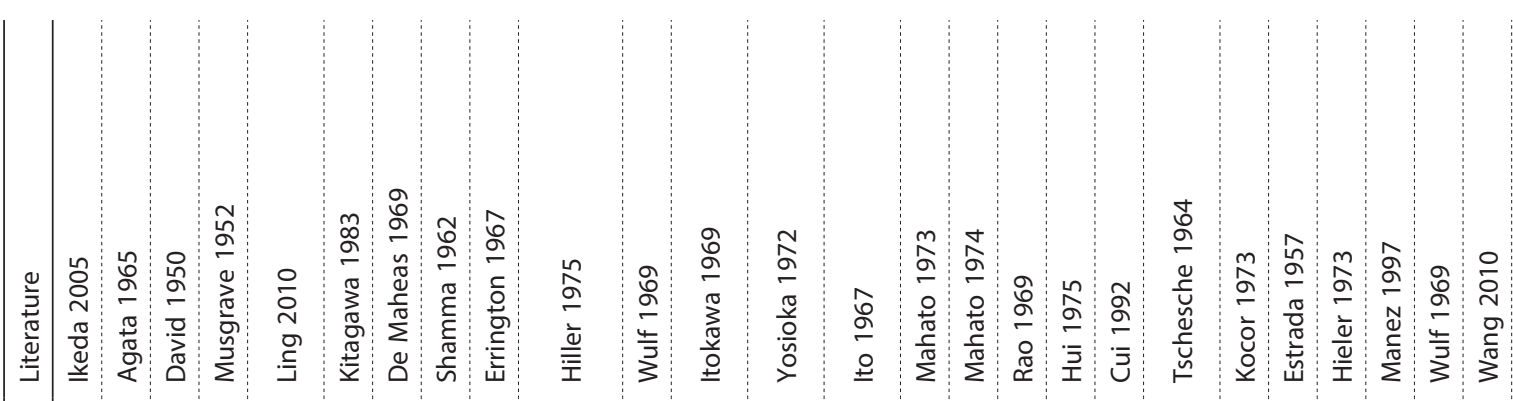

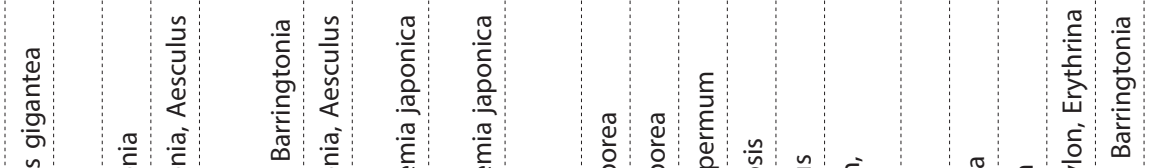

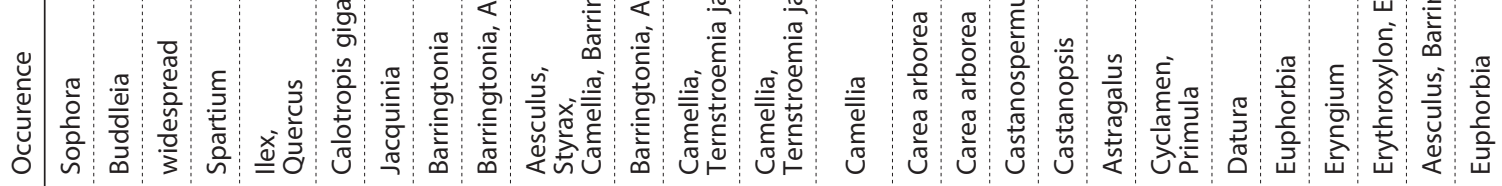

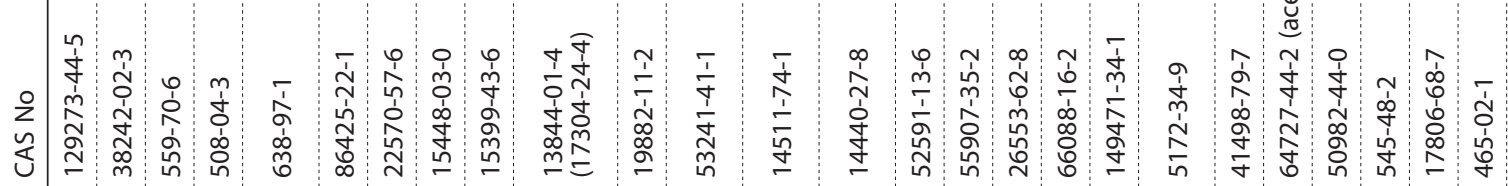

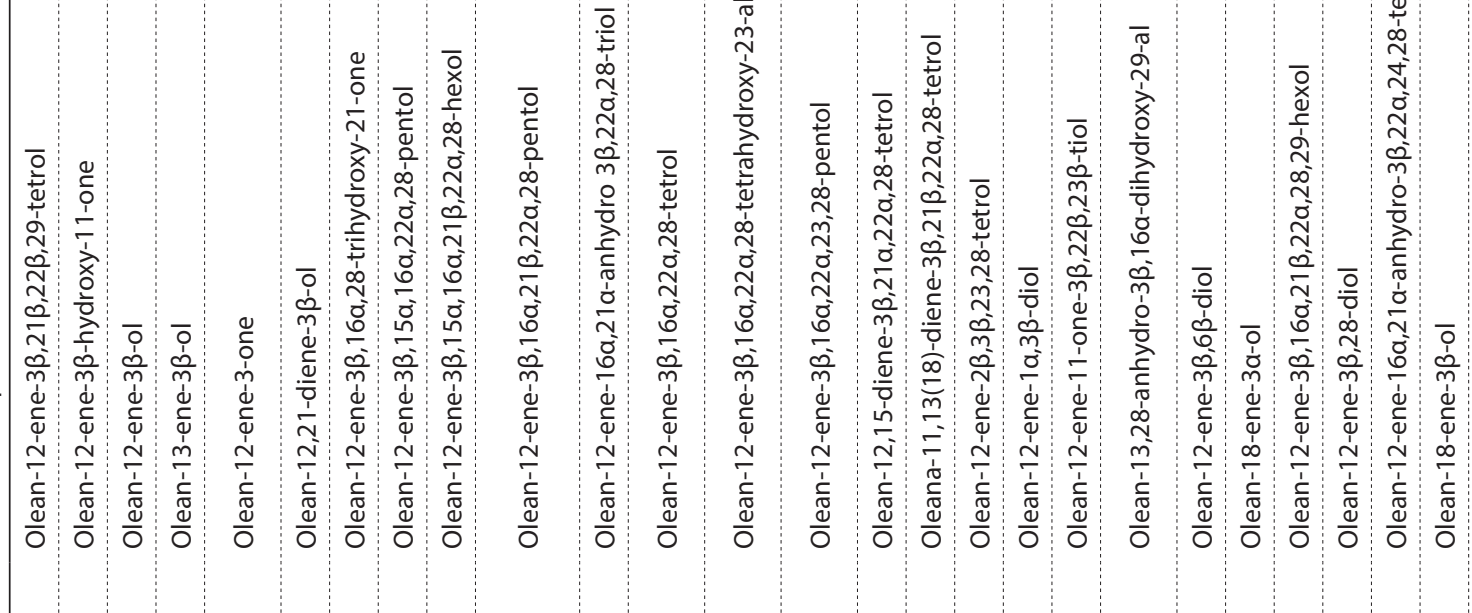

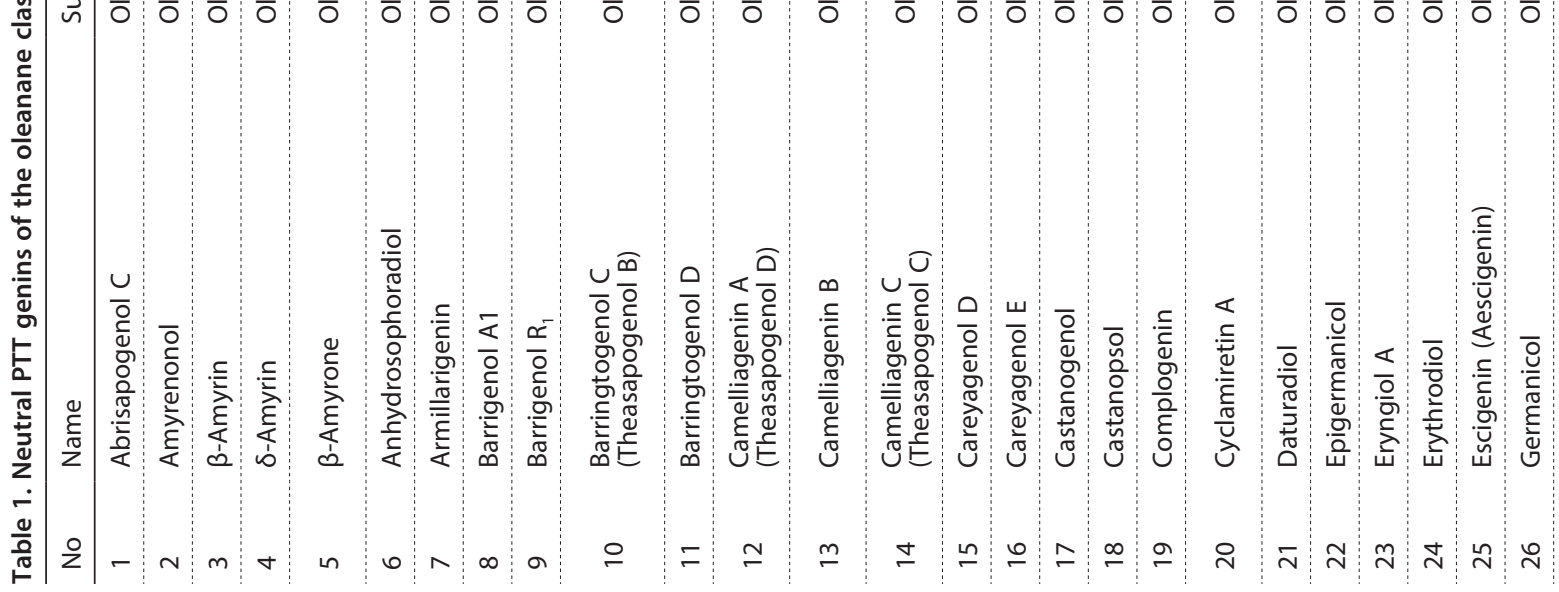




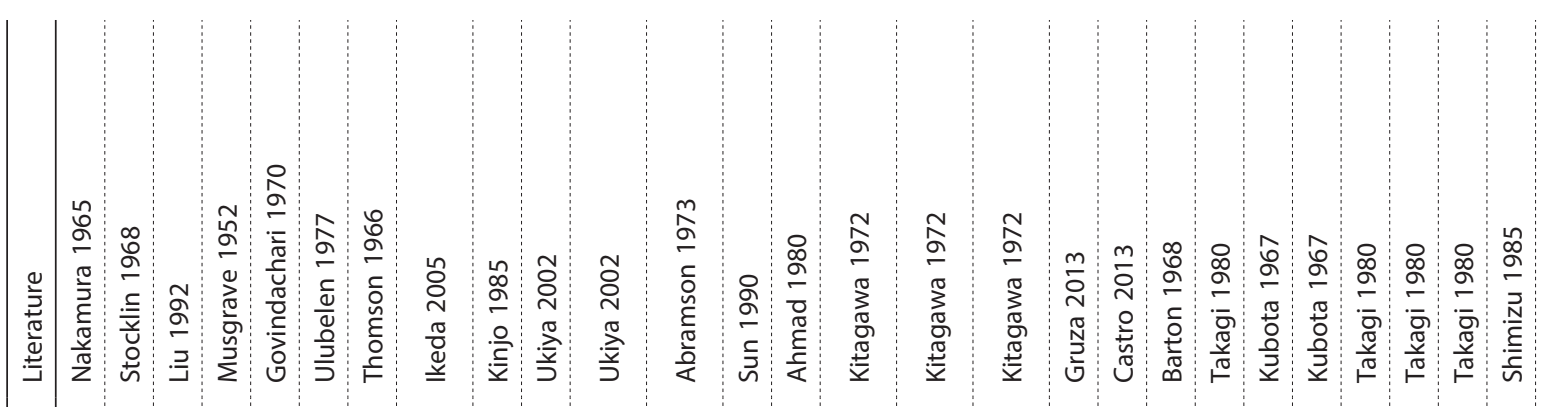

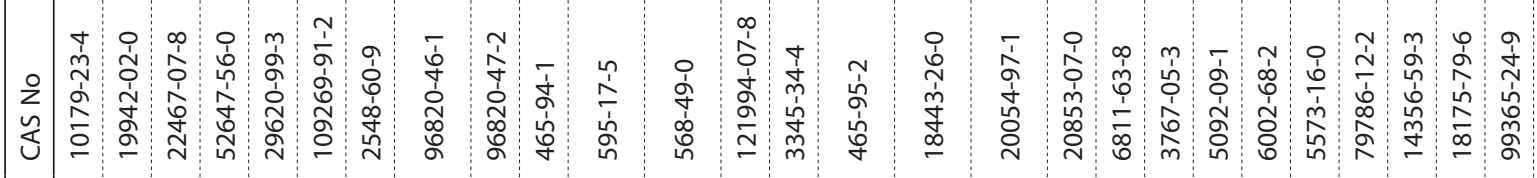

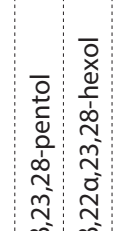

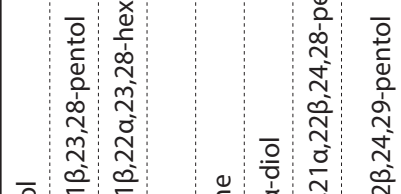

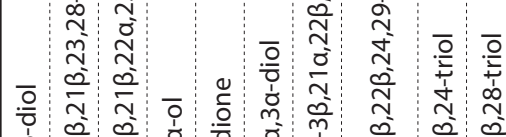

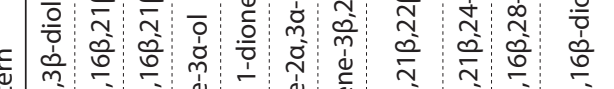

i

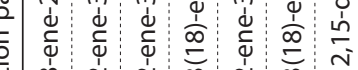

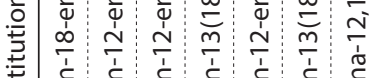

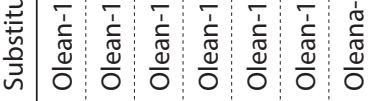

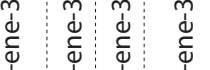

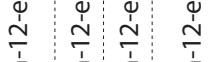

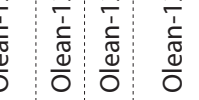

$\frac{2}{\frac{\pi}{0}}$

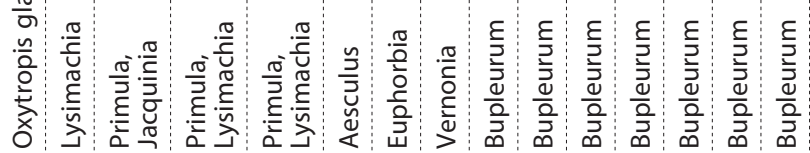




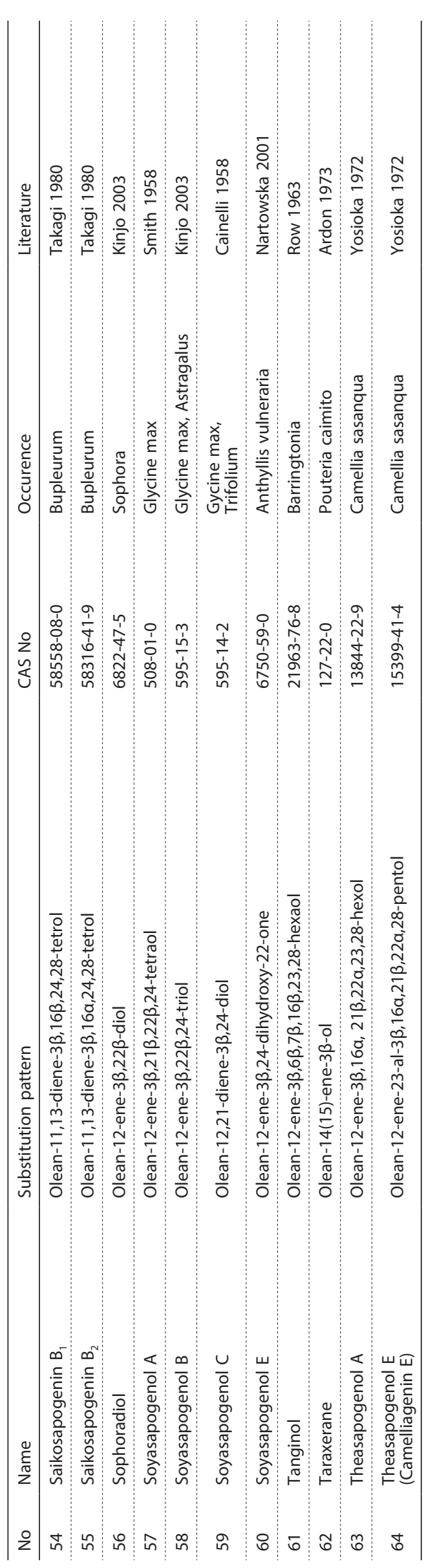

achievements of the art of academic molecular design and assembly, but having no practical value, they did not influence availability of PTT materials. Although it is known that in plants, the primary cyclization products of OSC are in turn a subject to subsequent oxidative transformations, which are performed by CYP type oxidases (Pollier et al., 2013; Geisler et al., 2013) the prospects of exploiting this knowledge in design of biotechnological processes (Moses et al., 2013) seems rather distant.

Majority of PT'T end up with $\beta-3-\mathrm{OH}$ group but secondary metabolic transformations can change it. Thus, $\beta$-amyrin corresponding 3-epi compound, called Pulcherrol has been found in Euphorbia pulcherrima and Eupatorium havanense. Their oxidation product: $\beta$-Amyrone (Pulcherrone) has been isolated from several plant sources. Isomeric 3-monoalkohols featuring $\Delta-13,18$ unsaturation are known under names: $\delta$-amyrin (3 $\beta$-) and gymnorhizol $(3 \alpha-)$, while $\Delta-18$ analogs are called germanicol and epigermanicol, respectively. Together with dienols, there are well over a dozen of single oxygen derivatives of pentacyclic oleanane hydrocarbon. Naturally, number of derivatives grows very quickly as consecutive substituents are introduced. Compounds 1-64 in Table 1 represent only a small fraction of known non-acidic derivatives of $\beta$-amyrin. They are collected together against phytochemical tradition pooling secondary metabolites of a particular plant, in order to demonstrate functional and stereochemical diversity within a single class of PTT, associated with one particular type of terpenoid skeleton. Some of the presented compounds are considerably more available than other, which is reflected in number of studies, going beyond chemical structure elucidation. The following short notes are intended to bring attention to particular PTTs, which show promise as biologically active compounds, either in terms of selectivity or efficacy.

\section{NONACIDIC OLEANENES WITH MULTIPLE FUNCTIONALITIES}

In comparison to some other triterpenes, like for example betulin, which belong to lupine class, and evoked enormous interest both: as biologically active compound in its own right, and also as a starting point for synthetic exploration towards better drug lead compounds, non-acidic oleanenes are much less developed as prospective pharmacophores. Only very recently several review papers brought attention to their potential (Salminen et al., 2008; Yadav et al., 2010; Podolak et al., 2010; Thoppil \& Bishayee, 2011; Liang et al., 2011; Bishayee et al., 2011; Parmar et al., 2013; Yin, 2012). These references concern PTT belonging to all structural types and concentrate on the most popular compounds, with relatively good availability. Yet, despite of growing interest, most PTT compounds from this category, like majority of compounds listed in Table 1, remain in obscurity as far as modern pharmacological research is concerned.

\section{Erythrodiol}

Erythrodiol (olean-12-ene-3ß,28-diol, Homoolestranol, 24 ), is present in olive pressing residues as well as many other plants, including such important agricultural crop as soy. Despite widespread occurence, chemical synthesis by one step reduction from easily available of 105 esters is a viable alternative to isolation. Its occurrence in olive oil rose some food safety concerns, soon dropped after toxicology examination. The therapeutic efficiency of erythrodiol on different experimental models of in- 
flammation has been reported (Manez et al., 1997; de la Puerta et al., 2000). Other biological activities discussed, include anticancer (Nishino et al., 1988) and antihypertensive effects (Rodriguez-Rodriguez et al., 2004).

\section{Longispinogenin}

Longispinogenin (olean-12-ene-3 $\beta, 16 \beta, 28$-triol, 36), is a constituent of flower extract of chrysanthemum (Chrysanthemum morifolium). It exhibits inhibitory effects on Epstein-Barr virus early antigen (EBV-EA) activation induced by the tumor promoter (Ukiya et al., 2002). The inhibitory effects of this compound were almost equivalent to or stronger than that of glycyrrhetinic acid, which is a potent antitumor promoter (Konoshima et al., 1999).

\section{Soyasapogenols}

Soyasapogenols have been relatively well studied because their source — soybeans (Glycine max Merrill) constitute one of the most important agricultural crop and basis for food technology in the global scale. In the past, soy protein used to contain several non-nutrient impurities, like phytic acid derivatives, isoflavones and saponins, all considered undesirable but difficult to remove because of similar physicochemical properties. Isoflavones recoverable from soy technology waste materials, have made their way to innumerable food supplements as phytoestrogens. To our knowledge soy saponins (and their corresponding genins) have not yet surfaced as commercial products (Zhang \& Popovich, 2009) but their potential should not be underestimated. Among PT'T genins derived from soy, the main constituent soyasapogenol B: olean-12-ene-3 $\beta, 22 \beta, 24$-triol (58), stands out as the compound with pronounced antiviral (HSV-1) activity (Ikeda et al., 2005). Interestingly, corresponding tetraol - soyasapogenol $\mathrm{A}$, is much less active, which contradicts simple idea that more functionality renders better efficacy.

\section{Kudzusapogenols}

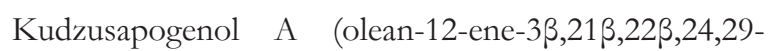
pentol) is the principle genin of Pueraria lobata root saponins but closely related kudzusapogenols $\mathrm{B}$ and $\mathrm{C}$ are also known. Their structure is closely related to genins of soya and horse chestnut, featuring C-24 primary hydroxyl group. The plant has rather special status in traditional Chinese medicine (TCM) as an agent against vertigo, headache and migraine. Its present applications against alcohol dependance are connected with the presenece of isoflavone - puearrine. The genins have been examined for antiviral activity and shown to perform similarly to soyasapogenols.

\section{Barringtogenols}

Barringtogenol C (olean-12-ene-3 $\beta, 16 \alpha, 21 \beta, 22 \alpha, 28$ pentol, 10) and barringtogenol D (olean-12-ene-16 $\alpha, 21 \alpha$ epoxy-3 $\beta, 22 \alpha, 28$-triol, 11) unlike many other sapogenins constitute triterpenoid framework for saponins found in numerous plant sources, leaves of Careya arborea, seeds of Aesculus hippocastanum L., seeds of Barringtonia acutangula or fruits of Styrax japonica. As a result, barringtogenol C is known under several names, like : Theasapogenol B, Jegosapogenol A, Saniculagenin D, Careyagenol A, Giganteumgenin M, Aescinidin, Acutangenol B. Although biological activities are much better recognized for their corresponding saponins, e.g. antiprotozoal activity against Leishmania donovani (Mandal et al., 2006), some prospects suggested for their antidiabetic applications warrant further interest and research (Yoshikawa et al., 1996).

\section{Gymnemagenins}

Among treasures of Ayurvedic medicine, gurmar (in Hindi: sugar destroyer), referring to Asclepiadaceae family herb - Gymnema sylvestre $\mathrm{R}$. Br., is one of the best recognized by Western modern pharmacognosy. Consumption of its leaves has profound effect on taste - it selectively suppresses response to sweeteners like sucrose, saccharin and cyclamate. Herbal preparations and plant extracts have been tested for variety of health supporting activities (anti-inflammatory, antibacterial, antiobesity, hypolypidemic) with positive results and gymnemic acids - glucuronides of partially acylated PTT — gymnemagenin have been found responsible for potent antidiabetic activity (Saneja et al., 2010; Patel et al., 2012). A sensitive HPLC-tandem MS analytical method for determination of gymnemagenin in rat plasma made it possible to monitor active principle dosing and to study pharmacokinetics (PK), following administration of variety Gymnema preparations (Kamble et al., 2013), since direct determination of gymnemic acids does not seem feasible. Careful chemical investigation of Gymnema constituents revealed very complex picture, in which oleanane glycosides: gymnemic acids, gymnemasins and gymnemasides, coexist with dammarane-type saponins, also named gymnemasides (Porchezhian \& Dobiryal, 2003). Many patents have been filed for health care applications of Gymnema where genins are claimed for beneficial effect, along with their glycosides.

\section{Theasapogenins}

Tea leaves processing gives opportunity to isolate saponin concentrates which are rich in PT'Ts. These material attained position of commodities in food industry and applications in other technical capacities, like cosmetics, paints and plastics related processes. In this respect, their situation is much like for soysasaponins whereas scale effect exert pressure for applications. Thus far theasapogenins, and accompanying cammeliasapogenins are not yet available as chemically certified materials. Nevertheless, potential of theasapogenols A, B, E and cameliagenins $\mathrm{A}$ and $\mathrm{D}$ as highly functinalized oleanenes and prospective molecular probes is obvious (Morikawa et al., 2006).

\section{Escigenins}

Aesculus hippocastanum L., decorative tree widespread throughout of moderate and sub-tropical climat zone has been known for curative properties of its seed extract (HSE) since the time immemorial. Ethnopharmacological tradition of HSE application for prevention and treatment of vascular ailments stand well against modern clinical criteria. Contemporary phytochemical studies list extensive group of saponins derived from partly acylated PTT compounds - all escins, isoescins and aesculiosides (isolated from $A$. chinensis Bunge), can be attributed to four genins: protoescigenin, barringtogenol C, barringtogenol D and escigenin. Although HSE is an active principle of numerous herbal preparations, neither saponins nor sapogenins are available as individual chemicals (with exemption of couple phytochemical standards sold in miligram quantities). Recent elaboration of a process for isolation and purification of protoescigenin 44 affords new opportunity for research in this area (Gruza et al., 2013). 


\section{CARBOXYLIC ACIDS FROM OLEANENE GROUP}

There are eight methyl substituents present in most PTT belonging to oleanane class and they can be subject of enzymatic oxidation, resulting in primary alcohols, corresponding aldehydes and carboxylic acids but phytochemical studies reveal that probability of such biotransformation vary greatly for particular methyl positions. PTT natural products bearing carboxylic functions are widespread, particularly as genins of bisdesmosidic saponins which are characterized by unique structural feature - combining in one molecule two oligosaccharide chains with distinctly different types of linkage: one glycosidic, typically placed in position 3 and one glycosyl ester involving terpene carboxylic group and anomeric position of an oligosaccharide. Since acidic PT'T are relatively easily separable from the bulk of neutral secondary metabolites they became a forefront materials for various technical applications and became subjects of countless patents, which are not listed. Acidic PT'T (in some cases known only as genins of particular saponins) are collected in Table 2 .

\section{Oleanolic acid}

Olean-12-ene-3 $\beta$-hydroxy-28-oic acid (oleanolic acid, $105)$ is one of the most widespread secondary metabolites (Pollier \& Goossens, 2012) - it has been isolated from more than 1620 dicotyledone plant species! Its synonyms include: Astriantiagenin C, Caryophylin, Giganteumgenin C, Gledigenin 1 and Virgaureagenin B, which clearly indicates its presence in various saponins. Its occurrence in unconjugated form is often observed in plant waxes serving as physical barrier to pathogens attack and preventing water loss. First isolated over a century ago, it has a long story of chemical investigation but its high resolution X-ray structure was determined only recently (Froelich \& Gzella, 2010) Plant originated 105 is a result of common cyclase activity (BAC), followed by three step oxidation of $\mathbf{3}$, carried out sequentially on C-28 methyl group by cytochrome enzyme classified as CYP716A12 (Scheme 1 and Scheme 2). Many medicinal plants, such as Panax ginseng; Hedera helix; Calendula officinalis; Thymus vulgaris; Rosmarinus officinalis, Viscum album, etc., have been shown to contain oleanolic acid, often together with other PTT components. Presently, the principal source of 105 , turned commercial, are olive oil manufacturing process waste materials. Olive tree (Olea europaea, Oleaceae) leaves, collected together with olives during harvest contain about 3\% of unconjugated oleanolic acid. Considering large scale of olive oil manufacturing (ca. 4 mln metric tonnes per annum) this secondary metabolite could be considered marketable specialty chemical. Unfortunately, its pricing as a chemical reagent does not favor widespread research. Thus far, 105 has a status of active pharmaceutical ingredient (API) only in China, but it is also present in innumerable OTC (over the counter) multicomponent herbal preparations aimed at pharmaceutical, nutritional and cosmetic markets, globally. In line with predicted growing demand for the compound, there are also ongoing $\mathrm{R} \& \mathrm{D}$ projects towards novel biotechnological processes utilizing cloned or expressed in bacteria enzymes from triterpene biosynthetic cascade, targeting $\mathbf{1 0 5}$ as well as other PT'T secondary metabolites.

A list of pharmacological activity of $\mathbf{1 0 5}$ is extensive. It is an antioxidant in more than one sense: as a free radical scavenger but also as an inducer of the Nfr2 mediated expression of catalase and glutathione synthase. Hepatoprotec-

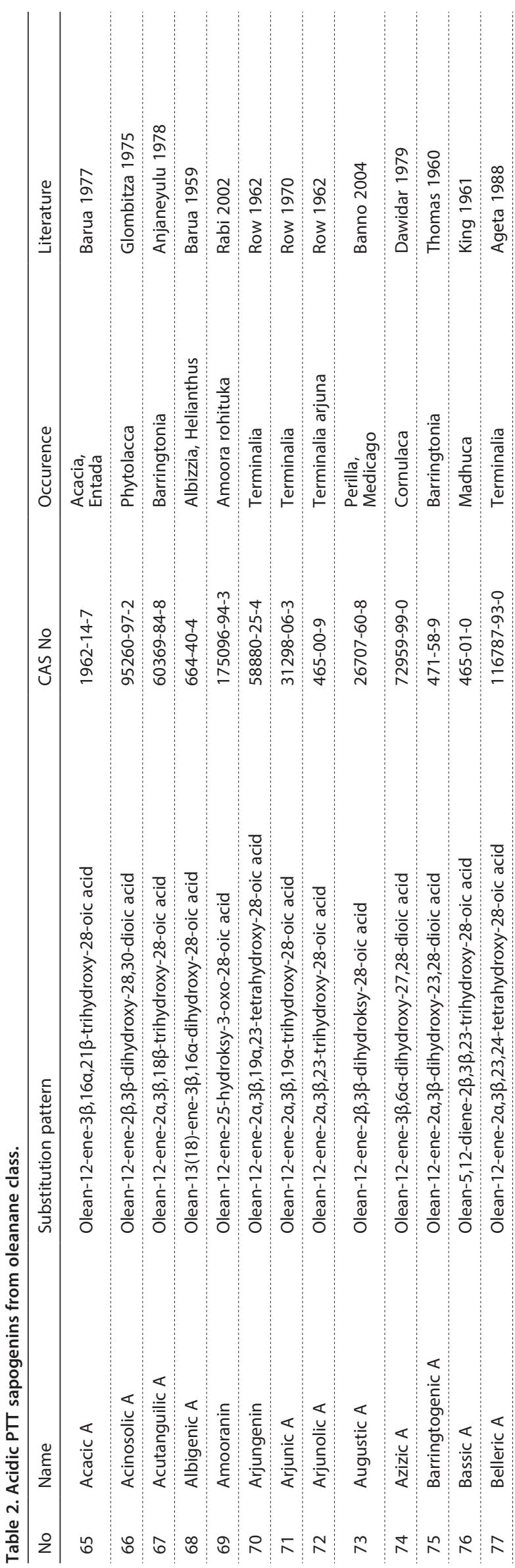




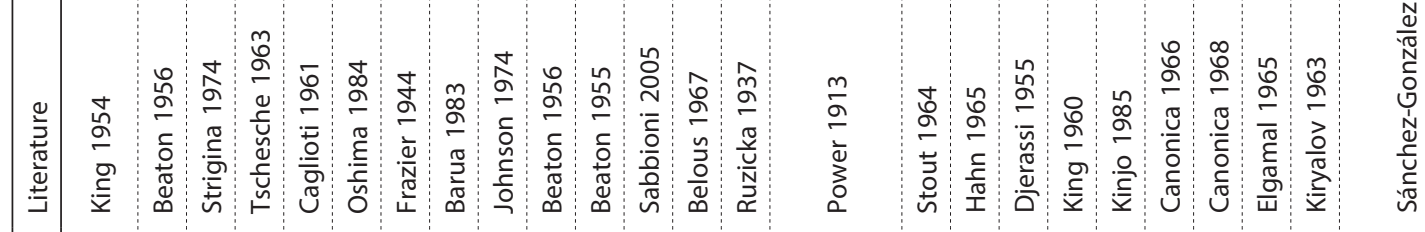

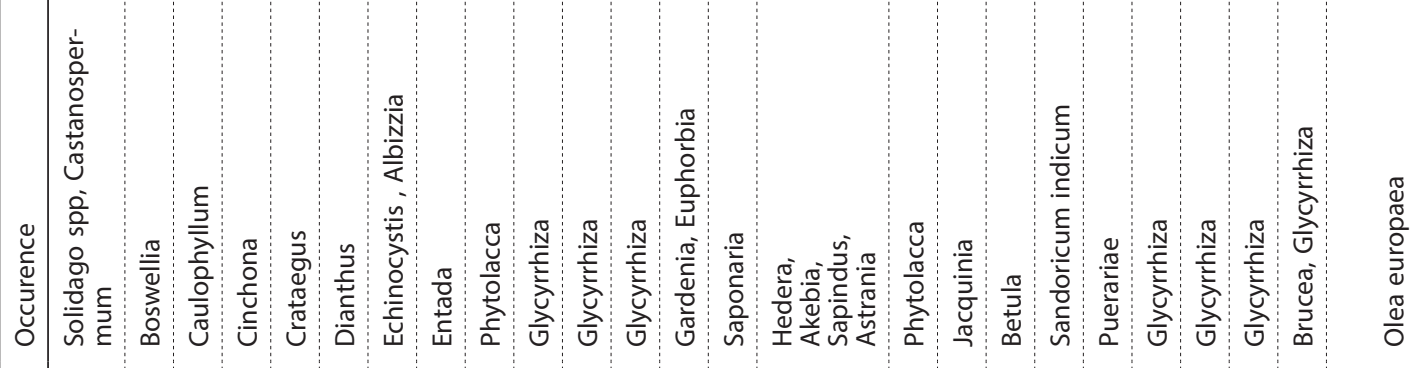

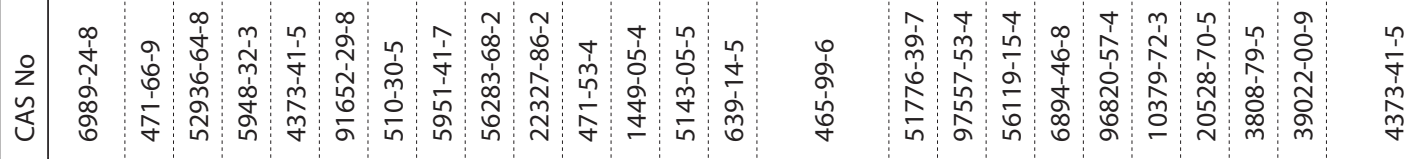

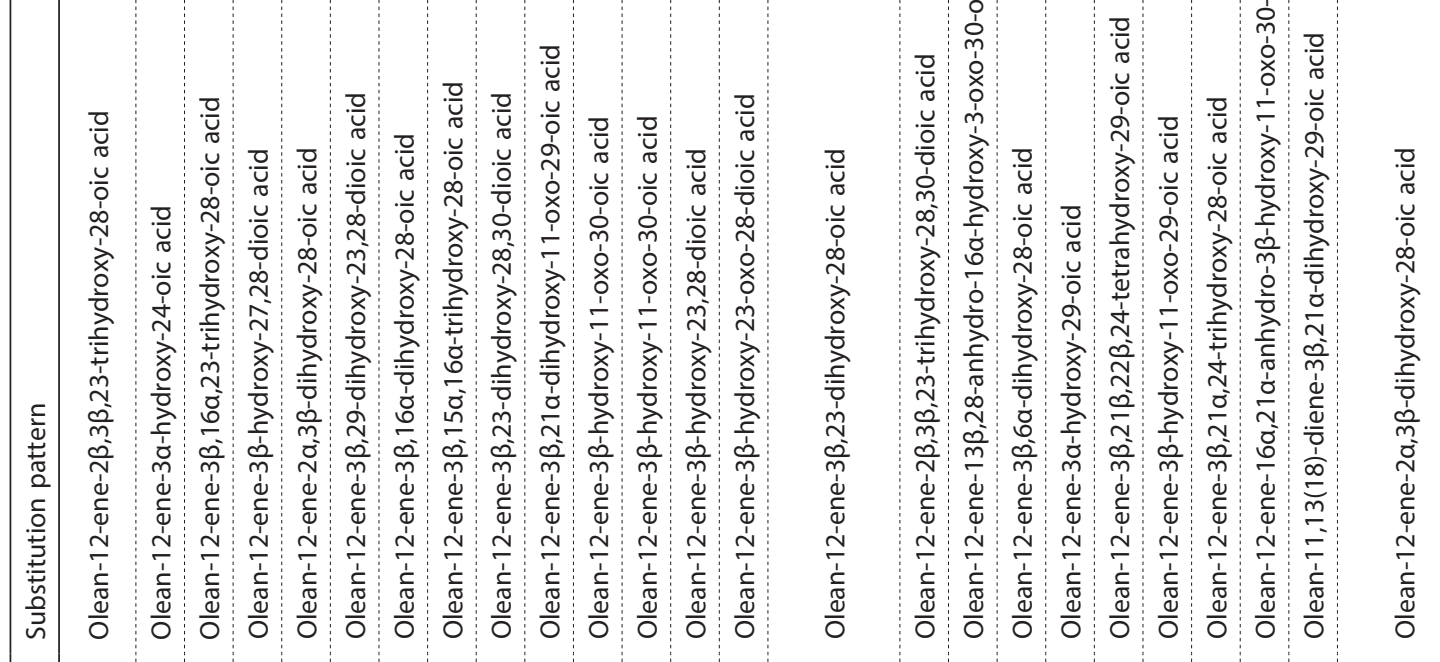

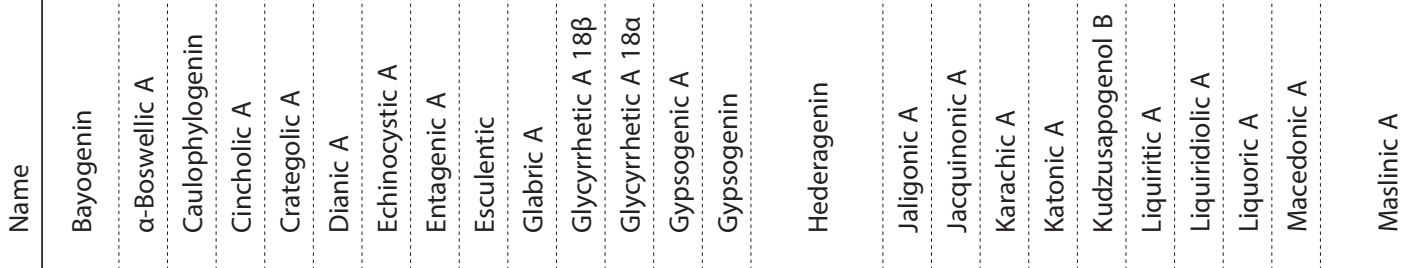

이 


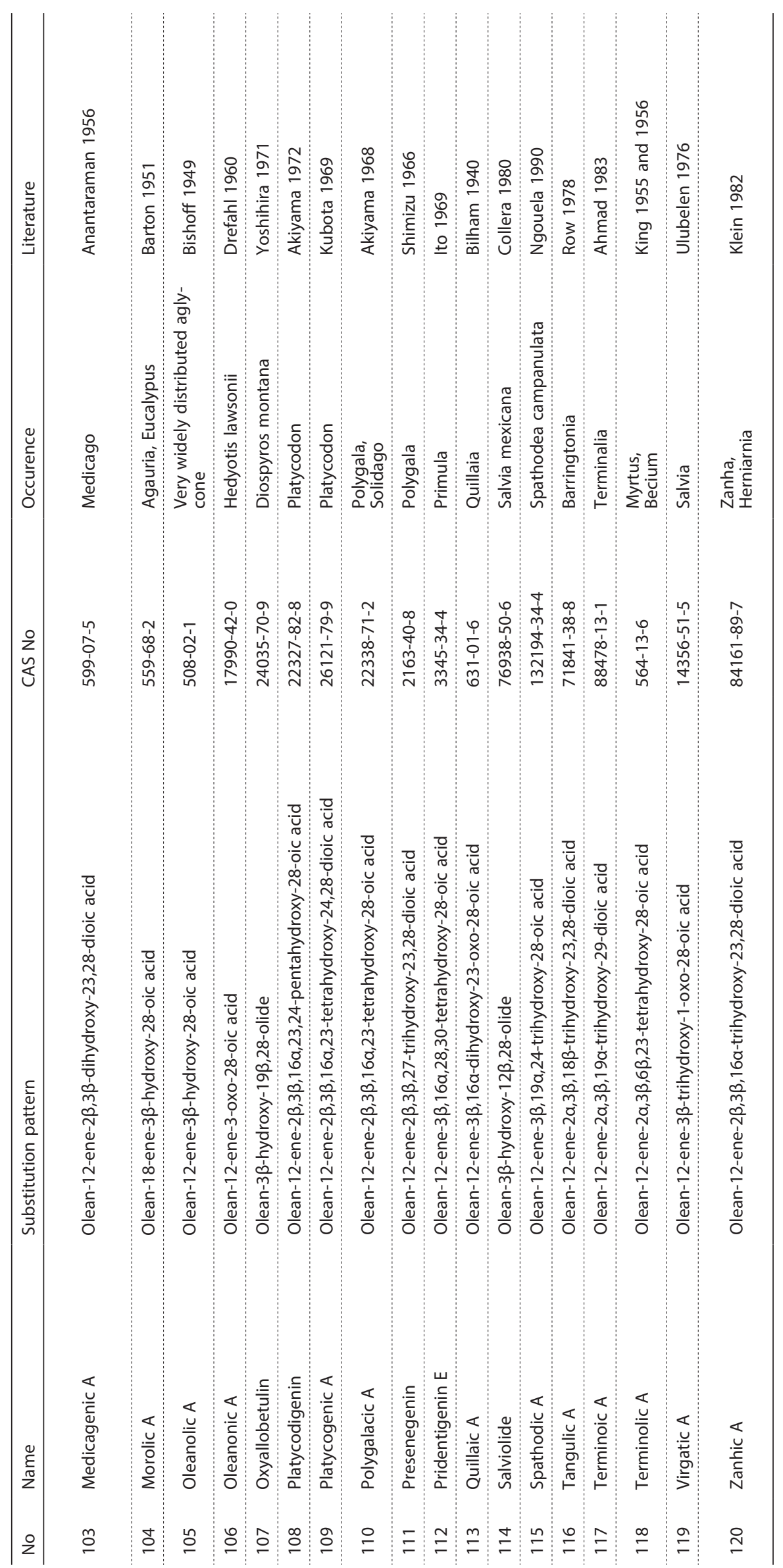




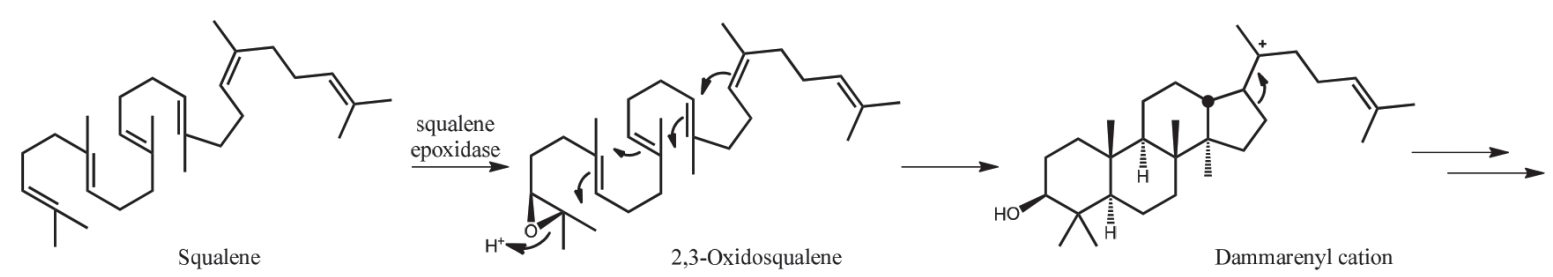

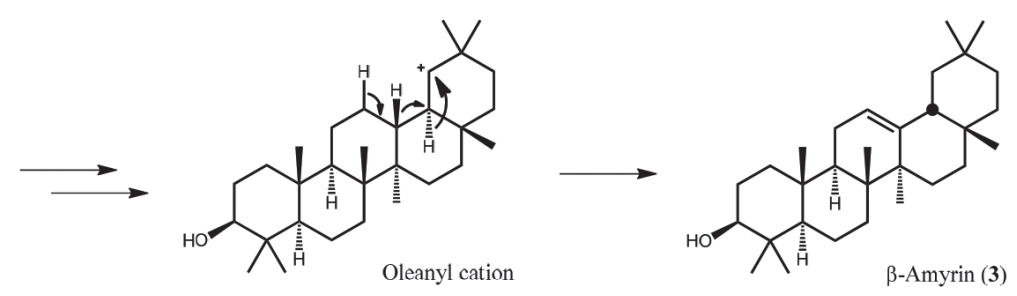

Scheme 1. The key intermediates of the squalene cyclization to $\beta$-amyrin.

tive effects of the acid was demonstrated to operate in case of acute poisonings as well as in chronic diseases (Pollier \& Goossens, 2012). Another biological activity proven on molecular level are interaction with farnesyl receptor FXR and suppression of some oxidative enzymes from CYP family. At the same time, the compound has been proven to be a potent inducer of the metabolic phase 2 response. Detailed structure-activity relationship, which lists effects of 105 in molecular and cellular pharmacology tests, was reviewed for oleanane and ursane triterpenoids (Sun et al., 2006). Additionally, anti-inflammatory, anti-hiperlipidemic, anti-HIV and anticancer activities of $\mathbf{1 0 5}$ have been reported (Zeng et al., 2012). Observed modulation of immune-inflamatory markers by the compound suggests therapeutic implications for multiple sclerosis (Martin et al., 2012). Obviously, such a collection of biological properties, potentially advantageous in prophylaxis and clinic, warrant further research on 105 and its new derivatives.

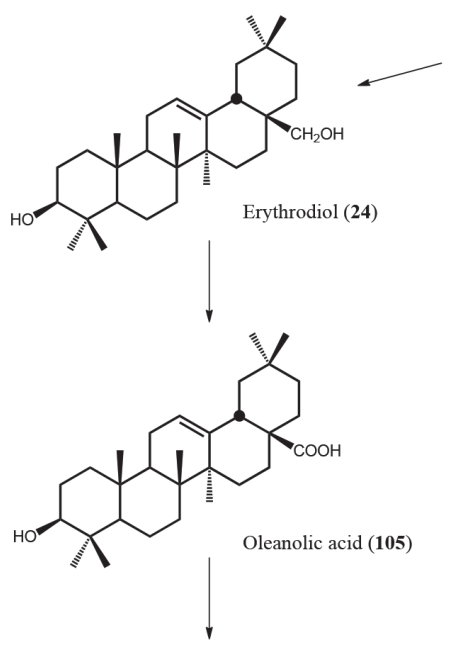<smiles>CC1(C)CCC2(O)CC[C@]3(C)C(=CCC4C5(C)CC[C@H](O)C(C)(C)C5CC[C@]43C)C2C1</smiles><smiles>CC1(C)CCC2(O)CC[C@]3(C)C(=CCC4C5(C)C[C@H](O)[C@@H](O)[C@](C)(C(=O)O)C5CC[C@]43C)C2C1</smiles>

$\beta-$ Amyrin (3)<smiles>CI</smiles>

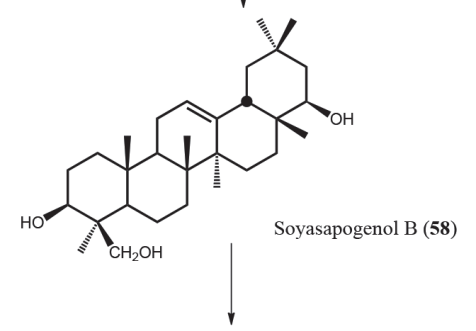

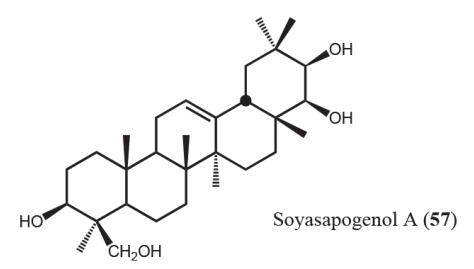

Scheme 2. Two lines of oxidative transformations of $\beta$-amyrin, carried out by CYP716A12 and CYP93E2, respectively. 


\section{Glycyrrhetinic acid}

Root of the herb liquorice (Glycyrrbiza glabra L; Fabaceae) is known for ages as a source of sweetening agent - glycyrrhizic acid, di-glucuronide of PTT sapogenin: glycyrrhetinic acid (88, also called enoxolone), which can be easily obtained in pure state by hydrolysis of liquorice saponins. Salts of $\mathbf{8 8}$ with alkaline metals are industrial raw materials, manufactured on thousand tonns scale for use in food industry. Diammonium glycyrrhizinate is an anti-hepatic drug and the sapogenin similarly has strong pharmaceutical connotations. Under name: enoxolone it is known as an antiinflamatory remedy for topical use and disodium salt of its hemisuccinate, carbenoxolone has been developed in Great Britain as a drug to treat peptic ulcer (Farina et al., 1998). It is speculated that anti-inflamatory action of $\beta$-glycyrrhetinic acid (88) is caused by inhibition of steroidal of $11 \beta-h y-$ droxylase (Kroes et al., 1997). Of increasing interests are also semi-synthetic derivatives of $\mathbf{8 8}$ with antitrombotic activity (Graebin et al., 2010). New generation of sweeteners emerged from replacement of hydroxyl function with amine group (Ijichi et al., 2005). Since the native liquorice saponins perform well in studies of supramolecular effects leading to new pharmaceutical formulations, it has been postulated that $\mathbf{8 8}$ could also be used for such purposes. It has to be mentioned that position of conjugated unsaturation in glycyrrhetinic acid enables chemical isomerization of the ring junction $\mathrm{D} / \mathrm{E}$ - thus glycyrrhetinic is know in two diastereoisomeric forms: $18 \beta-(\mathbf{8 8})$ and $18 \alpha-(\mathbf{8 9})$. Following successful entry of 102 derivative CDDO into experimental pharmacology other acidic sapogenins have been engaged in exploratory chemistry along parallel lines. Thus $\mathbf{8 8}$, arjunolic acid 71 and $\alpha$-boswellic acid 79 (usually used in a native mixture with $\beta$-regioisomer, which is ursane analog) have been converted into unsaturated cyanoketones, as prospective new antiiinflamatory agents (Subba Rao et al., 2008; Chadalapaka et al., 2008).

\section{Quillaic acid}

The bark of Chilean soap tree (Quillaja saponaria Molina) has been a source of commercial saponin material since more than a half century. Although the main interest in Quillaja commodity resides in its application in food industry as detergent, foaming and/or wetting agent and emulsifier, some of the individual saponins have been found to exert potent immunoenhancing activity (Sun et al., 2009), which started scientific investigation of both: saponins and their common sapogenin — quillaic acid (113). The main difference between 113 and other acidic sapogenins presented here resides in intermediate oxidation level of C-23 — the aldehydo function placed there offers unique opportunity to derivatize or conjugate the triterpene moiety by chemistry unavailable for more frequently encountered $-\mathrm{OH}$ or $-\mathrm{COOH}$ functional groups. Although 113 and its esters have been tested for antinociceptive activity (Arrau 2011), its primary application in research remains to be that of a glycoside acceptor in syntheses of bis-desmosidic saponins with immunoadjuvant function (Adams et al., 2010; Ragupathi et al., 2011)

\section{Hederagenin}

Hederagenin (92) is a common sapogenin for terpenoid glycosides found, among others, in common ivy (Hedera helix) and edible Chenopodium quinoa. As a component of fructus Akebiae extract, widely used in traditional
Chinese medicine, it has been recognized as a potent anti-depressant. Hederagenin is able to exert neuropharmacological activity by influencing serotonin and dopamine transport. It has been shown to reduce stress signs as effectively as citalopram, a proven antidepressant (Zhou et al., 2010). Analytical methods for determination of 92 in body fluids were developed, following suggestion that it might be an active metabolite of native saponins (Yang et al., 2011).

\section{Maslinic acid}

Maslinic acid (102) is a close structural analog of OLA (it differs only with one additional hydroxyl group, placed at $2 \alpha-)$ and likewise is a secondary metabolite of olive tree (Olea europaea L). Since it occurs chiefly in the fruits, and its content in olive oil ranges from about 300 to $1300 \mathrm{mg} / \mathrm{kg}$, its significance in human nutrition is considerable. The compound has been examined in rodent model for possible harmful effects of large doses, in hematology, clinical biochemistry and histopathology examinations, with negative results (Sanches-Gonzales et al., 2013). In a rodent study of intervention in diet-induced hyperlipidemia, both: 102 and 105 were shown to exert favorable modulations in gene expression and inhibition of the intestinal absorption and storage of cholesterol (Liu et al., 2007). C-2 epimer of the maslinic acid is called augustic acid (73) and it is important sapogenin in its own right. In a program striving for PT'T compounds with anti-HIV activity, 102 was coupled by an amide bond with several amino acids and peptides (Parra et al., 2010). It has been demonstrated that some derivatives obtained in this way exhibited distinct activity, associated with two particular steps of the virus life cycle: entry and maturation.

\section{Arjunolic acid and Bayogenin}

Arjunolic acid (72) and bayogenin (78) represent another pair of C-2 epimeric sapogenins, both occurring in variety of plants, and both having significant record of use in ethnomedicine. Bark of the Indian tree from Combretaceae family - Terminalia arjuna is recognized as a source of 72 (a laboratory isolation process affords $210 \mathrm{mg}$ from $2 \mathrm{~kg}$ bark; (Hemalatha et al., 2010) and at the same time it is indicated as cardiac tonic with additional antilipidemic, antiinflammatory, antioxidant, and immunomodulatory properties, which evoked vivid interest in its molecular pharmacology (Gosh \& Sil, 2013). While Indian researchers preferred to work on the samples of natural origin, Chineese scientists elaborated efficient synthesis of the title compounds from OLA (11 steps, about 10\% yield) (Wen et al., 2010). The key step involved Baldwin's cyclopalladation reaction and resulted in conversion of C-24 methyl group into acetoxymethyl substituent (Baldwin et al., 1985; Neufeldt \& Sanford, 2010). The semisynthetic compounds thus obtained have been examined for inhibitory activity against glycogen phosphorylase. Contrary to the initial expectations, introduction of either C-23 or C-24 hydroxyl group resulted in the loss of inhibitory potency. Remarkably, arjunolic acid 72 has been presented in chemical literature as a novel, renewable material with prospective applications in supramolecular chemistry and nanoscience (Bag et al., 2008). Structural features like a rigid pentacyclic backbone, extending over a distance $1.32 \mathrm{~nm}$ with hydroxyl and carboxylic groups at the opposite ends have been underlined as a suitable platform for development of various chemical constructs with programmed functions. 


\section{PENTACYCLIC TRITERPENES AS AN INSPIRATION FOR CHEMISTRY AND PHARMACOLOGY}

Western ethnopharmacology contains numerous examples of PTT rich plants being used as remedies for acute as well as chronic ailments, which are today classified as inflammation related pathologies. Many more such examples can be cited from Ayurvedic and traditional Chinese medicine. Recent advances in separation techniques and structural analysis helped to realize that traditional pharmacognosy, concentrating on saponins as the main active principles containing PTT, does not offer a full picture of terpenoid plant secondary metabolite potential. Although some multicomponent saponine concentrates are still used as active pharmaceutical ingredients (API; a notable example of escines from Aesculus hippocastanus L.), more attention is paid to individual sapogenins, particularly these available in high chemical purity. Contemporary academic chemical synthesis is a combination of sophisticated art and high technology, for which there is practically no limit within low molecular weight natural products. Thus, principal PTT, such as 3, 102, 105 etc., have been synthesized by total synthesis, both in racemic and enantiomeric variants (Surendra \& Corey, 2009). Hydroxylated oleanene carboxylic acids, which became active principles of herbal preparations from dietary supplements category, are also starting materials for synthesis of new analogs, which reveal high potency in many modern pharmacological tests. Thus semisynthetic derivatives of $\mathbf{1 0 2}$ described in more detail below (CDDO), suppress action of inducible enzymes iNOS and COX-2, which renders them valuable tools to study anti-inflammatory effects (Liu 2005). The same group of derivatives induce apoptosis of cancerous cells, in acute myelogeneous leukemia, among others (Konopleva et al., 2004).

\section{SEMISYNTHETIC DERIVATIVES OF OLEANENE}

Considerable heterogeneity of such enzymes as squalene epoxide cyclases (OSC), heme related monooxidases (P450) and glycosyltransferases (GTS), which take place in multistep processes completing assembly of natural terpenoid glycosides, render them particularly difficult objects of study because as plant secondary metabo- lites they tend to cluster as multicomponent mixtures of compounds with very similar physicochemical properties. Both: saponins and sapogenins are as a rule devoid of chromophoric groups, therefore are very difficult to separate by classical analytical methods, including chromatography using UV detection. Complex polycyclic structures of PT'T with multiple centers of chirality, naturally attracted attention of synthetic chemists as an exceptional challenge, fit to test most sophisticated methods available. For decades leading academic laboratories perfected their total synthetic approaches to natural triterpene frameworks. The results of the endeavor spanned from syntheses of racemic germanicol, $\beta$-amyrin, $\delta$-amyrin and lupeol during 1970-ties (Ireland et al., 1973; Johnson et al., 1993) to successful design and execution of highly enantioselective assembly of several oleanenes and lupeol by EJ Corey (Surendra \& Corey 2009) nearly 40 year later. However, these great accomplishments in the art of organic synthesis have not attained a level of practical applicability. Above quoted syntheses well exceeded 30 sequential steps and overall yields were usually much lower than 1\%. Similarly, despite of great advances in plant secondary metabolites biosynthesis and biotechnology, there are no processes other than agriculture follow up isolation, available for manufacturing triterpenoids. Therefore, growing demand for pure chemical compounds from PTT category has to be satisfied by semi-synthesis, and not surprisingly carboxylic acids of natural origin stand out as suitable raw materials, since they are easier to isolate and refine to purity than neutral sapogenins. It should be mentionrd that carbocation rearrangement concept, important for rationalizing diverse biomimetic cyclization pathways, has found some practical application. Thus, lupane - oleanane transformation based on Wagner-Meerwein rearrangement turned out synthetically useful reaction in case of both: betuline and betulinic acid, which are easily available starting materials (Salvador et al., 2012) (Scheme 3).

Short review of oleanolic acid chemistry presented below is intended to serve as an illustration of useful interconversions of typical natural oleanene functionality into new, more pharmacophoric modes of substitution. The three functional groups of 105: $3 \beta$-secondary hydroxyl, $\Delta$ 12,13- trisubstituted double bond and 17-carboxylic group, placed within triterpene framework, have been re-

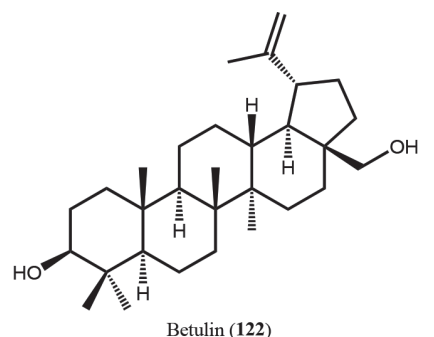

Betulin (122)

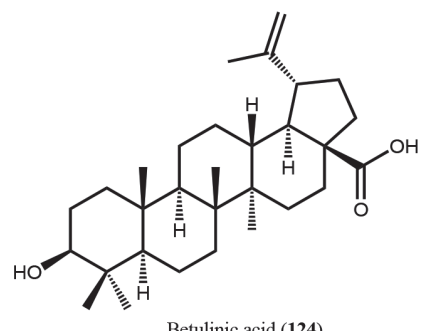

Betulinic acid (124)

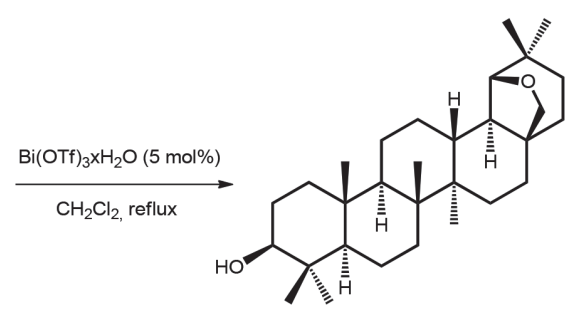

Allobetulin (123)

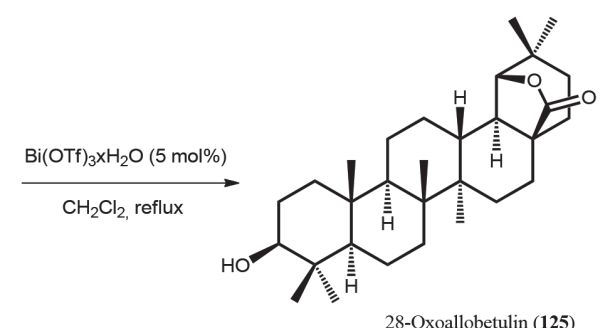

Scheme 3. Bismuth triflate-catalyzed Wagner-Meerwin rearrangement from lupanes do oleanene core. 
peatedly exploited for standard synthetic transformations, Thus $3 \beta$-ol secondary hydroxyl group is a key point for glycosylations and/or acylations, while after oxidation to ketone it activates vicinal position for further C-X type functionalization. Double bond serves for direct additions (hydroxylation, epoxidation) as well as for an activation of the allylic positions. Finally, carboxylic group is utilized for both: protective esterification or active ester or amide bond type derivatization. In particular, triterpenoid carboxylic acids have been used as scaffolds in multidirectional syntheses on solid support, with use of specially designed linkers (Wang \& Fang, 2011). It should be mentioned, however, that common functionalities placed within PTT framework can feature some unexpected reactivity characteristic. While $3 \beta$-ol susceptibility towards acylating, alkylating and oxidating reagents corresponds well with typical cyclohexanol substrate, the remaining functions exhibit reduced reactivity reflecting steric constraint of their vicinity. The carboxylic group can be converted into esters by action of diazomethane or carboxylate salts alkylation by electrophilic halogenealkanes, but esters thus formed do not undergo hydrolysis under typical basic conditions. The $\Delta-11,12$ double bond is not saturable during catalytic hydrogenation and it is not cleaved during ozonolysis. Additionally, action of other oxidative reagents result in introduction of $\mathrm{C}-\mathrm{O}$ function into protected $105\left(\mathrm{CrO}_{3}\right.$ affords unsaturated 11-oxo product and peroxoacetic acid gives 12-ketone) (Farina et al., 1998). These limitations did not seriously hampered a program of semisynthesis from available substrates such as $\mathbf{1 0 5}$ (and isomeric ursolic acid), which brought into being hundreds of new chemical entities, and shed light on PT'T potential in drug discovery, during pharmacological studies carried out in last decades.

Discussing 105 as starting material for exploratory syntheses should be preceeded by information of its role in natural TPP preparation. Conversion to erythrodiol, which involves only one functional group transformation (reduction of C-28 carboxylic function to corresponding primary alcohol) may be considered trivial, preparation of maslinic acid requires, beside carboxylic protection selective hydroxylation at C-2, but elaboration of hyptatic or myriceric acid. A syntheses proved much more chal- lenging, because it required chemical oxidative transformation of a specific methyl group. One successful solution of such problem, namely Baldwin's catalytic activation of C-23 methyl group (Baldwin et al., 1985; Neufeldt \& Sanford, 2010) is depicted on Scheme 4 below.

Carboxylic groups of acidic PTT have been functionalized in many ways. When not designated for engagement in an anomeric esterification as in desmosidic saponins, it could be protected as alkyl or benzyl ester in O-alkylation protocol, to facilitate selective transformation of other functionalities. Formation of an amide bond was frequently applied for conjugation with pharmacologicaly desirable substituents. In a project aimed at novel cytotoxic agents, 105 was conjugated with biologically active natural product — dehydrozingerone, which involved a phenol group esterification, usually considered very susceptible to chemical as well as biological degradation (Tatsuzaki et al., 2007). Application of esterification procedure involving EDCI (1-(3-dimethylaminopropyl)3-ethylcarbodiimide hydrochloride) in the presence of DMAP (4-dimethylaminopyridine) resulted in formation of several suitably stable P'T'T esters which have shown significant cytotoxic effects.

The leading line of chemical modifications of 105 which started with introduction of enone system into ring $A$, continued with repetition of the transformations in ring $\mathrm{C}$, extension of the conjugated bond system and additional derivatizations. Typical reaction sequence involved conversion of a secondary hydroxyl group into ketone, followed by vicinal substitution-elimination reaction carried out by halogenating or seleno-organic reagents (Sporn et al., 2011). Syntheses, which were guided by inhibition of iNOS test, further led to C-2 formylation with ethyl formate, followed by oxazole ring closure with hydroxylamine and subsequent ring fission with sodium methoxide, which left C-2 cyano substituent allowing for crucial modification of 2-ene-3-one arrangement, present in the original lead compound TP-46 (CDDO) (Konopleva et al., 2004; Sporn et al., 2011; Liby \& Sporn, 2012).

Drug candidate TP-151 (2-cyano-3,12-dioxooleana-1,9(11)-dien-28-oic acid; CDDO) selected during the extensive synthetic program carried out by MB Sporn and collaborators, was recognized as a selective Michael
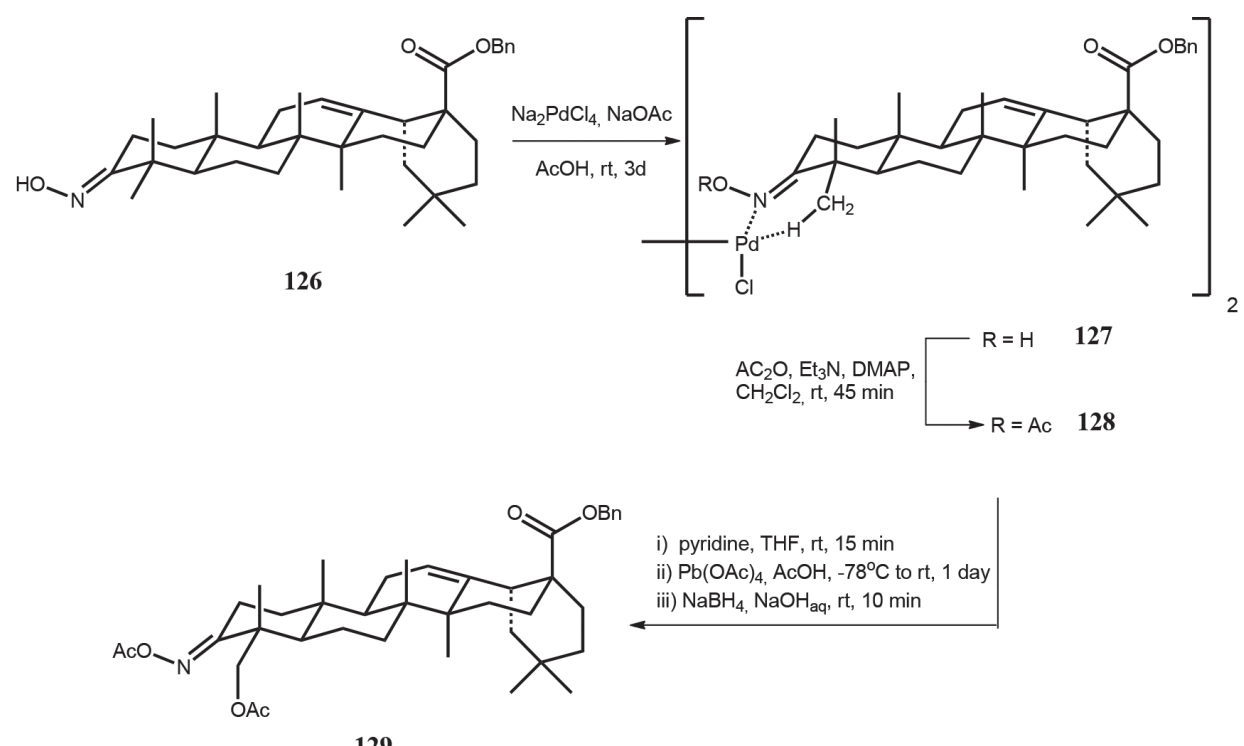

129

Scheme 4. Catalytic activation and formal hydroxylation of C-23 methyl group. 


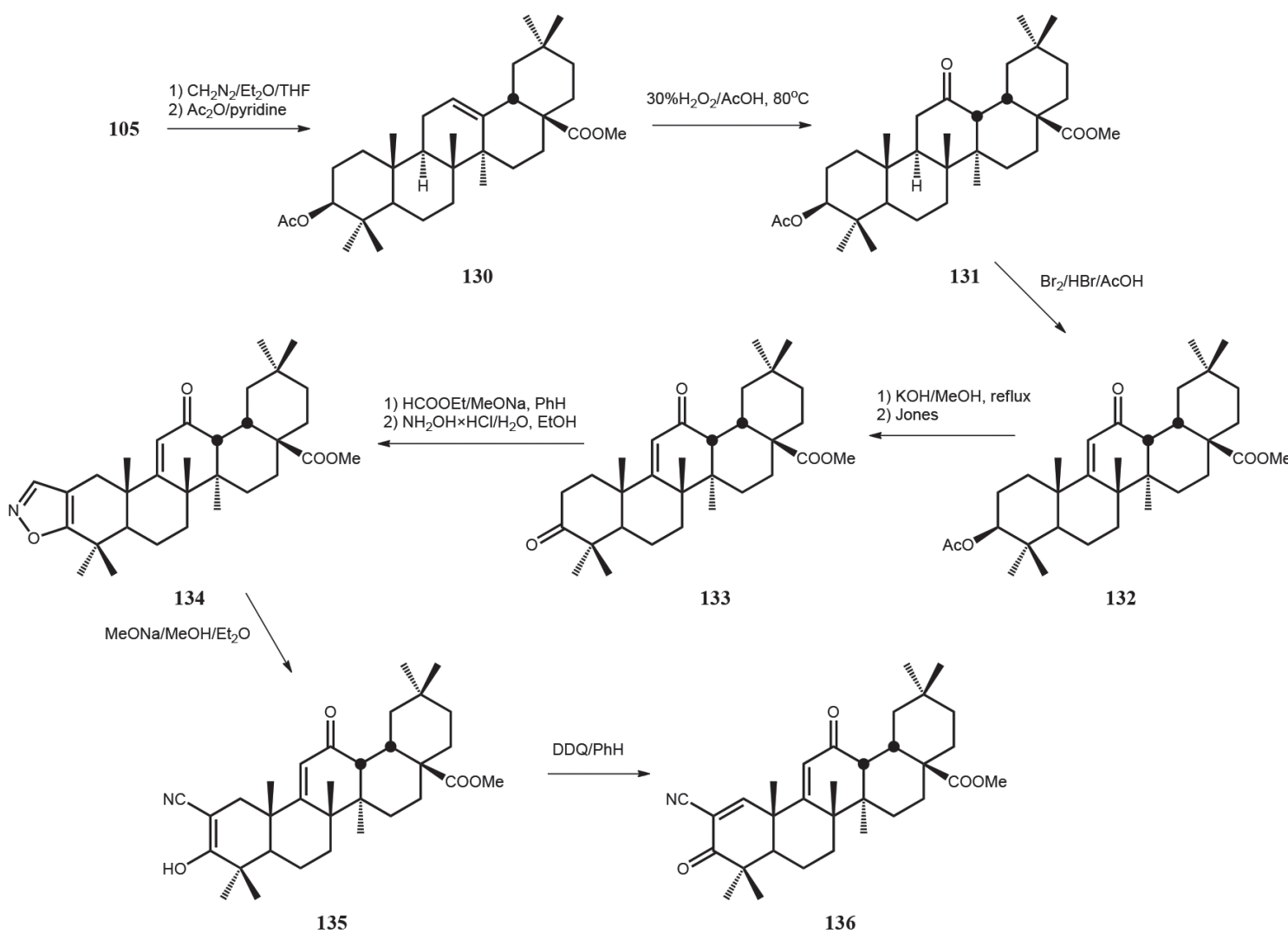

Black dots represent $\beta$ - positioned hydrogen atoms, thus indicating stereochemistry of the ring junctions.

Scheme 5. Synthesis of the drug candidate CDDO from protected oleanolic acid (105).

acceptor covalently but reversibly interacting with endogenous S- nucleophiles such as glutathione or cysteine residues, although no isolable adducts were obtained in chemical experiments. The original idea to find PT'T based inhibitor of inflammatory process was highly successful, providing effective (low nanomolar) inhibitor of inducible $\mathrm{NO}$ synthase, also effective as inhibitor of COX-2 and inflammatory cytokins. Under name bardoxolone methyl (XX) it started, under auspices of Reata Pharmaceuticals (Dallas, TX, USA) parallel clinical trials, first to assess its anticancer properties and later towards advanced chronic kidney disease in patients with type 2 diabetis (Pergola et al., 2011). In parallel with Phase 1 clinical trials XX synthesis was elaborated into five-step scalable process, proceeding in about $50 \%$ overall yield from 105 (Fu \& Gribble, 2013). Evident antioxidant and anti-inflammatory action, believed to operate via induction of transcription factor Nrf2, which reduces activity of the IKK $\beta / N F x B$ pathway suggested possibility of various other therapeutic indications. Eventually bardoxolone BEACON clinical study was terminated for safety concerns (Tayek \& Kalantar-Zadeh, 2013).

Thus agent CDDO Me has failed in the most important indication, despite shining performance (results) in preclinical study, but inspired many developmental activities, which may prove very important for next PT'T drug candidates, which are likely to come along soon. Initial problems with synthesis and formulation were solved, through persistent and effective work towards new prodrug versions (e.g. C-28 imidazolide and analogs) of the active substance, which offers promise of new generation API. Process chemistry for semi-synthesis for
CDDO analogs is clearly in sight (Fu \& Gribble, 2013), which may be taken as an encouragement to start SAR supported exploratory chemistry with numerous polyhydroxyl analogs of $\mathbf{1 0 5}$.

Among many other attempts to exploit 105 as a lead for new drugs synthetic motifs of lactonization should be mentioned. It has been noticed that its treatment with ozone did not cleave ring $\mathrm{C}$ double bond as expected. Instead, additional ring was formed, linking carbons 13 and 28 by ester linkage (Sun et al., 2006). Similar lactonization is observed when 105 is treated with bromine in acetic acid solution. Concomitant introduction of a substituent at C-12 can be handy for further functionalization (Pollier \& Goossens, 2012). Another type of lactones can be formed by Bayer-Villiger oxidation of cyclic ketones. This transformation has been exploited for the ring A cleavage and examination of biological activity of 3,4-seco structures derived from PTT via two-step oxidation of $3 \beta$ alcohols (Maitraie et al., 2009). Possibility of a regioselective exocyclic C-2 chain formation, started by base catalysed formylation seems to have much wider scope than thus far demonstrated formation of A-fused heterocyclic ring formation (Chen et al., 2008). Many 3 -O-esters of 105, designed as better soluble and more available congeners have been prepared and tested for biological activity (Pollier \& Goossens, 2012). Recently, another example of 105 based SAR and development of its derivative as a new lead compound have been described. A Chinese group, working towards development of new HCV entry inhibitors has found that carboxylic group of 105 and its C-16 vicinity are the modifiable and structure sensitive sites, while the rest of molecule 
should be conserved to sustain antiviral activity $\mathrm{Yu}$ et al., 2013). In summary amount of synthetic studies performed on oleanolic acid and its derivatives greatly outnumbers reactions carried out on neutral polyhydroxylic oleanenes isolated directly from plants or obtained from saponins by their controlled degradation.

\section{CONCLUSIONS}

Oleanene class of naturally occurring PT'T contains some hundreds of individual chemicals (giving rise to much larger set of natural secondary derivatives through biogenetic diversification caused by action of acylating enzymes and glycosyltransferases; similarly, application of synthetic chemistry can easily multiplicate any subgroup of natural PTT), which should be treated as an invaluable renewable resource of structural diversity, with multiple prospective applications, primary in the human healthcare. Selected 120 PT'T structures (1-120) presented in this review, represent an unique set of closely related compounds with high affinity to biopolymeric assembly performing cell biochemistry processes. Split into approximately even collections of neutral and acidic sapogenins, this arbitrary selected sub-library of triterpenoid plant metabolites provides representative overview of structures and chemotypes encountered in $\mathrm{Na}$ ture, thus far only partially explored for prospective lead compounds. The main lesson learned from biological activity studies of natural and semi-synthetic oleanenes unanimously prove that the compounds function well in biological environment (in other words: they are inherently biocompatible) exhibiting multitarget functional interactions in micro- and even millimolar concentrations. These compounds are characterized by multitarget activities, which are in principle tunable by chemical modifications. This characteristic suits well novel ideas in drug discovery, which challenge current paradigm, focusing on one molecular target approach (Medina-Franco et al., 2013). Simple chemical concepts, like utility of a Michael acceptor element (represented in Nature within glycirrhetinic acids), has led to useful development in both: PTT semisynthesis and pharmacology. It seems fair to speculate that idea of reversible binding of reactive protein nucleophiles (e.g. cystein -SH groups) is generally sound, but extended molecular framework (preferably polycyclic) and supplementary functional groups $(-\mathrm{OH}$, esters, ketones, carboxyls, amide etc.) are needed to make it properly selective for expected pharmacological effect. Thus, described oleanene family of PTT represent natural library apparently rich in prospective lead compounds.

\section{Acknowledgements}

This paper was inspired, and partly supported, by project under European and Regional Funds POIG.0101.0214-072/09-00 grant contract agreement. Support from Pharmaceutical Research Institute statutory fund is also gratefully acknowledged.

\section{REFERENCES}

Adams MM, Damani P, Perl NR, Won A, Hong F, Livingston PO, Ragupathi G, Gin DY (2010) Design and synthesis of potent Quillaja saponin vaccine adjuvants. J Am Chem Soc 132: 1939-1945.

Arrau S, Delporte C, Cartagena C, Rodríguez-Díaz M, González P, Silva X, Cassels BK, Miranda HF (2011) Antinociceptive activity of Quillaja saponaria Mol. saponin extract, quillaic acid and derivatives in mice. J Ethnopharmacol 133: 164-167.
Augustin JM, Kuzina V, Andersen SB, Bak S (2011) Molecular activities, biosynthesis and evolution of triterpenoid saponins. Phytochemistry 72: 435-457.

Azimova SS (2013) Triterpene glycosides: Natural compounds. Plant sources, structure and properties, Springer, New York.

Bag BG, Dey PP, Dinda SK, Sheldrick WS, Oppel IM (2008) A simple route for renewable nano-sized arjunolic and asiatic acids and self- assembly of arjuna-bromolactone. Beilstein J Org Chem 4: DOI:10.3762/bjoc. 4.24 .

Baldwin JE, Jones RH, Najera C, Yus M (1985) Functionalization of unactivated methyl groups through cyclopalladation reactions. Tetrabedron 41: 699-711.

Bishayee A, Ahmed S, Brankov N, Perloff M (2011) Triterpenoids as potential agents for the chemoprevention and therapy of breast cancer. Front Biosci 16: 980-996.

Chadalapaka G, Jutooru I, McAlees A, Stefanac T, Safe S (2008) Structure-dependent inhibition of bladder and pancreatic cancer cell growth by 2 -substituted glycyrrhetinic and ursolic acid derivatives. Bioorg Med Chem Lett 18: 2633-2639.

Chen J, Gong Y, Lin J, Hua W, Zhang L, Sun H (2008) Synthesis and biological evaluation of novel pyrazolo $(4,3-b)$ oleanane derivatives as inhibitors of glycogen phosphorylase. Chem Biodiv 5: 1304-1312.

de la Puerta R, Martinez-Dominguez E, Ruiz-Gutierrez V (2000) Effect of minor components of virgin olive oil on topical anti-inflammatory assays. Zeitschrift für Naturforschung 55: 814-819.

Dinda B, Debnath S, Mohanta BC, Harigaya Y (2010) Naturally occurring triterpenoid saponins. Chem Biodivers 7: 2327-2580.

Eschenmoser A, Arigoni D (2005) Revisited after 50 Years: the 'stereochemical interpretation of the biogenetic isoprene rule for the triterpenes. Helv Chim Acta 88: 3011-3050.

Eschenmoser A, Ruzicka L, Jeger O, Arigoni D (1955) Zur Kenntnis der Triterpene. 190. Eine Stereochemische Interpretation der Biogenetischen Isoprenregel bei den Triterpenen. Helv Chim Acta 38: 1890-1904.

Farina C, Pinza M, Pifferi G (1998) Synthesis and anti-ulcer activity of new derivatives of glycyrrhetic, oleanolic and ursolic acids. Il Farmaco 53: 22-32.

Froelich A, Gzella AK (2010) Oleanolic acid ethanol monosolvate, Acta Cryst E 66: o2790. DOI:10.1107/S1600536810039929.

Fu L, Gribble GW (2013) Efficient and scalable synthesis of bardoxolone methyl (CDDO-methyl Ester). Organic Lett 15: 1622-1625.

Fukushima O, Seki H, Ohyama K, Ono E, Umemoto N, Mizutani M, Saito K, Muranaka T (2011) CYP716A Subfamily members are multifunctional oxidases in triterpenoid biosynthesis. Plant Cell Physiol 52: 2050-2061.

Geisler K, Hughes RK, Sainsbury F, Lomonossoff GP, Rejzek M, Fairhurst S, Olsen CE, Motawia MS, Melton RE, Hemmings AM, Bak S, Osbourn A (2013) Biochemical analysis of a multifunctional cytochrome P450 (CYP51) enzyme required for synthesis of antimicrobial triterpenes in plants. Proc Natl Acad Sci USA 110: 3360-3367.

Ghosh J, Sil PC (2013) Arjunolic acid: A new multifunctional therapeutic promise of alternative medicine. Biochimie 95: 1098-1109.

Graebin CS, Verli H, Guimaraes JA (2010) Glycyrrhizin and glycyrrhetic acid: scaffolds to promising new pharmacologically active compounds. J Braz Chem Soc 21: 1595-1615.

Gruza MM, Jatczak K, Zagrodzki B, Laszcz M, Koziak K, Malińska M, Cmoch P, Giller T, Zegrocka-Stendel O, Woźniak K, Grynkiewicz G (2013) Preparation, purification and regioselective functionalization of protoescigenin - the main aglycone of escin complex. Molecules 18: 4389-4402.

Hemalatha T, Pulavendran S, Balachandran C, Manohar BM, Puvanakrishnan R (2010) Arjunolic acid: A novel phytomedicine with multifunctional therapeutic applications. Indian J Exp Biol 48: 238-247.

Hill RA, Connolly JD (2013) Triterpenoids. Nat Prod Rep 30: 10281065.

Hostettmann K, Marston A (2005) Saponins. Cambridge University Press, Cambridge.

Ijichi S, Tamagaki S (2005) Molecular design of sweet tasting com-

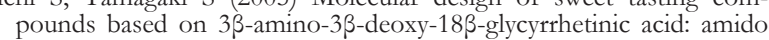
functionality eliciting tremendous sweetness. Chem Lett 34: 356-357.

Ikeda T, Yokomizo K, Okawa M, Tsuchihashi R, Kinjo J, Nohara T, Uyeda M (2005) Anti-herpes virus type 1 activity of oleanane-type triterpenoids. Biol Pharm Bull 28: 1779-1781.

Ireland RE, Dawson MI, Welch SC, Hagenbach A, Bordner J, Trus B (1973) Total synthesis of terpenes, XVIII. Convergent, stereoselective total synthesis of the unsymmetrical pentacyclic triterpene alnusenone. I Am Chem Soc 95: 7829-7841.

Johnson WS, Plummer MS, Reddy SP, Bartlett WR (1993) Cation-stabilizing auxiliaries in polyene cyclizations. 7 . The fluorine atom as a cation-stabilizing auxiliary in biomimetic polyene cyclizations. 4 . Total synthesis of dl- $\beta$-amyrin. J Am Chem Soc 115: 515-521.

Kamble B, Gupta A, Patil D, Khatal L, Janrao S, Moothedath I, Duraiswamy B (2013) Determination of gymnemagenin in rat plasma using high-performance liquid chromatography-tandem mass spectrometry: application to pharmacokinetics after oral administration of Gymnema sylvestre extract. Biomedical Chromatography 27: 669-675. 
Konopleva M, Tsao T, Estrov Z, Lee RM, Wang RY, Jackson CE, McQueen T, Monaco G, Munsell M, Belmont J, Kantarjian H, Sporn MB, Andreeff M (2004) The synthetic triterpenoid 2-cyano-3,12-dioxooleana-1,9-dien-28-oic acid induces caspase-dependent and -independent apoptosis in acute myelogenous leukemia. Cancer Res 64: 7927-7935.

Konoshima T, Takasaki M, Ichiishi E, Tokuda H, Nishino H, Duc NM, Kasai R, Yamasaki K (1999) Cancer chemopreventive activity of majonoside-R2 from Vietnamese ginseng, Panax vietnamensis. Cancer Lett 147: 11-16.

Kroes BH, Beukelman CJ, Van Den Berg AJJ, Wolbink GJ, Van Dijk H, Labadie RP (1997) Inhibition of human complement by $\beta$-glycyrrhetinic acid. Immunology 90: 115-120.

Liang Z, Zhang L, Li L, Liu J, Li H, Zhang L, Chen L, Cheng K, Zheng M, Wen X, Zhang P, Hao J, Gong Y, Zhang X, Zhu X, Chen J, Liu H, Jiang H, Luo C, Sun H (2011) Identification of pentacyclic triterpenes derivatives as potent inhibitors against glycogen phosphorylase based on 3D-QSAR studies. Eur J Med Chem 46: 2011-2021.

Liby KT, Sporn MB (2012) Synthetic oleanane triterpenoids: multifunctional drugs with a broad range of applications for prevention and treatment of chronic disease. Pharmacol Rev 64: 972-1003.

Liu J (2005) Oleanolic acid and ursolic acid: research perspectives. J Ethnopharmacol 100: 92-94.

Liu J, Sun H, Wang X, Mu D, Liao H, Zhang L (2007) Effects of oleanolic acid and maslinic acid on hyperlipidemia. Drug Development Research 68: 261-266.

Lodeiro S, Xiong Q, Wilson WK, Kolesnikova MD, Onak CS, Matsuda SP (2007) An oxidosqualene cyclase makes numerous products by diverse mechanisms: a challenge to prevailing concepts of triterpene biosynthesis. J Am Chem Soc 129: 11213-11222.

Maartmann-Moe K, Bicknell W, Francis GW (1987) Structure of olean12(13)-en-33-yl acetate. Acta Cryst C43: 2362-2364.

Maitraie D, Hung CF, Tu HY, Liou YT, Wei BL, Yang SC, Wang JP, Lin CN (2009) Synthesis, anti-inflammatory and antioxidant activities of $18 \beta$-glycyrrhetinic acid derivatives as chemical mediators of xanthine oxidase inhibitors. Bioorg Med Chem 17: 2785-2792.

Mandal D, Panda N, Kumar S, Banerjee S, Mandal NB, Sahu NP (2006) A triterpenoid saponin possessing antileishmanial activity from the leaves of Careya arborea. Phytochemistry 67: 183-190.

Manez R, Recio MC, Giver RM, Rios JL (1997) Effect of selected triterpenoids on chronic dermal inflammation. Eur J Pharmacol 334: 103-105.

Martin R, Hernandez M, Cordova C, Nieto ML (2012) Natural triterpenes modulate immune-inflammatory markers of experimental autoimmune encephalomyelitis: therapeutic implications for multiple sclerosis. British J Pharmacol 166: 1708-1723.

Medina-Franco JL, Giulianotti MA, Welmaker GS, Houghten RA (2013) Shifting from the single to the multitarget paradigm in drug discovery. Drug Discov Today 18: 495-501.

Morikawa T, Li N, Nagatomo A, Matsuda H, Li X, Yoshikawa M (2006) Triterpene saponins with gastroprotective effects from tea seed (the seeds of Camellia sinensis). I Nat Prod 69: 185-190.

Moses T, Pollier J, Thevelein JM, Goossens A (2013) Bioengineering of plant triterpenoids: from metabolic engineering of plants to synthetic biology in vivo and in vitro. New Pbytologist 200: 27-43.

Negi JS, Negi PS, Pant GJ, Rawat MSM, Negi SK (2013) Naturally occurring saponins: chemistry and biology. J Poison Med Plant Res $\mathbf{1}$ : 006-011.

Neufeldt SR, Sanford MS, (2010) O-Acetyl oximes as transferable directing groups for $\mathrm{Pd}$-catalyzed $\mathrm{C}-\mathrm{H}$ bond functionalization. Org Lett 12: 532-535.

Nishino H, Nishino A, Takayasu J, Hasegawa T, Iwashima A, Hirabayashi K, Iwata S, Shibata S (1988) Inhibition of the tumor-promoting action of 12-O-tetradecanoylphorbol-13-acetate by some oleanane-type triterpenoid compounds. Cancer Res 48: 5210-5215.

Parmar SK, Sharma TP, Airao VB, Bhatt R, Aghara R, Chavda S, Rabadiya SO, Gangwal AP (2013) Neuropharmacological effects of triterpenoids. Phytopharmacology 4: 354-372.

Parra A, Lopez PE, Garcia-Granados A (2010) Bioactive compounds with added value prepared from terpenes contained in solid wastes from the olive oil industry. Chem Biodiver 7: 421-439.

Patel K, Gadewar M, Tripathi R (2012) Pharmacological and analytical aspects of gymnemic acid: a concise report. Asian Pacific J Tropic Disease 2: 414-416.

Pergola PE, Raskin P, Toto RD, Meyer CJ, Huff JW (2011) Bardoxolone methyl and kidney function in CKD with type 2 diabetes. $N$ Engl J Med 365: 327-336.

Podolak I, Galanty A, Sobolewska D (2010) Saponins as cytotoxic agents: a review. Phytochem Rev 9: 425-474.

Pollier J, Goossens A (2012) Oleanolic acid. Phytochemistry 77: 10-15.

Pollier J, Moses T, González-Guzmán M, De Geyter N, Lippens S, Vanden Bossche R, Marhavy P, Kremer A, Morreel K, Guérin CJ, Tava A, Oleszek W, Thevelein JM, Campos N, Goormachtig S and Goossens A (2013) The protein quality control system manages plant defence compound synthesis. Nature 504: 148-52.
Porchezhian E, Dobriyal RM (2003) An overview on the advances of Gymnema sylvestre: chemistry, pharmacology and patents. Pharmazie 58: 5-12.

Ragupathi G, Gardner JR, Livingston PO, Gin DY (2011) Natural and synthetic saponin adjuvant QS-21 for vaccines against cancer. Expert Rev Vaccines 10: 463-470.

Rodríguez-Rodríguez R, Herrera MD, Perona JS and Ruiz-Gutiérrez V (2004) Potential vasorelaxant effects of oleanolic acid and erythrodiol, two triterpenoids contained in 'orujo' olive oil, on rat aorta. Brit J Nutrition 92: 635-642.

Salminen A, Lehtonen M, Suuronen T, Kaarniranta K, Huuskonen J (2008) Terpenoids: natural inhibitors of NF- $x \mathrm{~B}$ signaling with anti-inflammatory and anticancer potential. Cell Mol Life Sci 65: 29792999.

Salvador JAR, Silvestre SM, Pinto RMA, Santos RC, LeRoux C (2012) New Applications for bismuth(III) salts in organic synthesis: from bulk chemicals to steroid and terpene chemistry. Top Curr Chem 311: 143-178.

Sánchez-González M, Lozano-Mena G, Juan ME, García-Granados A, Planas JM (2013) Assessment of the safety of maslinic acid, a bioactive compound from Olea europaea L. Mol Nutr Food Res 57: 339-346.

Saneja A, Sharma C, Aneja KR, Pahwa R (2010) Gymnema sylvestre (Gurmar): A review. Der Pharmazia Lettre 2: 275-284.

Sheng H, Sun H (2011) Synthesis, biology and clinical significance of pentacyclic triterpenes: a multi-target approach to prevention and treatment of metabolic and vascular diseases. Nat Prod Rep 28: 543593.

Sporn MB, Liby KT, Yore MM, Fu L, Lopchuk JM, Gribble GW (2011) New synthetic triterpenoids: potent agents for prevention and treatment of tissue injury caused by inflammatory and oxidative stress. J Nat Prod 74: 537-545.

Subba Rao GSR, Kondaiah P, Singh SK, Ravanan P, Sporn MB (2008) Chemical modifications of natural triterpenes - glycyrrhetinic and boswellic acids: evaluation of their biological activity. Tetrahedron 64 : 11541-11548.

Sun H, Fang W-S, Wang W-Z, Hu C (2006) Structure-activity relationship of oleanane- and ursane-type triterpenoids. Botanical Studies 47: 339-368.

Sun H-X, Xie Y, Ye Y-P (2009) Advances in saponins-based adjuvants. Vaccine 27: 1787-1796.

Surendra H, Corey EJ (2009) A short enantioselective total synthesis of the fundamental pentacyclic triterpene lupeol. J Am Chem Soc 131: 13928-13929.

Tatsuzaki J, Taniguchi M, Bastow KF, Nakagawa-Goto K, Morris Natschke SL, Itokawa H, Baba K, Lee KH (2007) Anti-tumor agents 255: novel glycyrrhetinic acid - dehydrozingerone conjugates as cytotoxic agents. Bioorg Med Chem 15: 6193-6199.

Tayek JA, Kalantar-Zadeh K (2013) The extinguished BEACON of bardoxolone: not a monday morning quarterback story. $A m \mathrm{~J}$ Nephrol 37: 208-211.

Thoppil RJ, Bishayee A (2011) Terpenoids as potential chemopreventive and therapeutic agents in liver cancer. World J Hepatol 3: 228249.

Ukiya M, Akihisa T, Tokuda H, Suzuki H, Mukainaka T, Ichiishi E, Yasukawa K, Kasahara Y, Nishino H (2002) Constituents of Compositae plants: III. Anti-tumor promoting effects and cytotoxic activity against human cancer cell lines of triterpene diols and triols from edible chrysanthemum flowers. Cancer Lett 177: 7-12.

Wen X-A, Liu J, Zhang L-Y, Ni P-Z, Sun H-B (2010) Synthesis and biological evaluation of arjunolic acid, bayogenin, hederagonic acid and 4-epi-hederagonic acid as glycogen phosphorylase inhibitors. Chinese J Nat Med 8: 0441-0448.

Wang S, Fang W (2011) Design and synthesis of a dual linker for solid phase synthesis of oleanolic acid derivatives. Molecules 16: 47484763.

Xue Z, Duan L, Liu D, Guo J, Ge S, et al. (2012) Divergent evolution of oxidosqualene cyclases in plants. New Phytologist 193: 1022-1038.

Yadav VR, Prasad S, Sung B, Kannappan R, Aggarwal BB (2010) Targeting inflammatory pathways by triterpenoids for prevention and treatment of cancer. Toxins 2: 2428-2466.

Yang X, Li G, Chen L, Zhang C, Wan X, Xu J (2011) Quantitative determination of hederagenin in rat plasma and cerebrospinal fluid by ultra fast liquid chromatography-tandem mass spectrometry method. J Chromatography B 21: 1973-1979.

Yin MC (2012) Anti-glycative potential of triterpenes: a mini-review. BioMedicine 2: 2-9.

Yoshikawa M, Murakami T, Matsuda H, Yamara J, Murakami N, Kitagawa I (1996) Bioactive saponins and glycosides. III. Horse chestnut. (1): The structures, inhibitory effects on ethanol absorption and hypoglycemic activity of escins $\mathrm{Ia}, \mathrm{Ib}, \mathrm{IIa}, \mathrm{IIb}$ and IIIa form the seeds of Aesculus hippocastanum L. Chem Pharm Bull 44: 1454-1464.

Yu F, Wang Q, Zhang Z, Peng YY, Qiu YY, Shi YY, Zheng YX, Xiao SL, Wang H (2013) Development of oleanane-type triterpenes as a new class of HCV entry inhibitors. J Med Chem 56: 4300-4319. 
Zeng X-Y, Wang Y-P, Cantley J (2012) Oleanolic acid reduces hyperglycemia beyond treatment period with akt/foxo1-induced suppression of hepatic gluconeogenesis in type-2 diabetic mice. PLoS One 7: 42115-42115.

Zhang W, Popovich DG (2009) Chemical and biological characterization of oleanane triterpenoids from soy. Molecules 14: 2959-2975.
Zhou D, Jin H, Lin HB, Yang XM, Cheng YF, Deng FJ, Xu JP (2010) Antidepressant effect of the extracts from Fructus Akebiae. Pharmacol Biochem Behav 94: 488-495.

Zwenger S, Basu C (2008) Plant terpenoids: applications and future potentials. Biotech Molecul Biol Rev 3: 001-007. 